\title{
An Improved Inexact Two-Stage Stochastic with Downside Risk-Control Programming Model for Water Resource Allocation under the Dual Constraints of Water Pollution and Water Scarcity in Northern China
}

\author{
Chong Meng, Wei Li *, Runhe Cheng and Siyang Zhou
}

check for

updates

Citation: Meng, C.; Li, W.; Cheng, R.; Zhou, S. An Improved Inexact

Two-Stage Stochastic with Downside Risk-Control Programming Model for Water Resource Allocation under the Dual Constraints of Water Pollution and Water Scarcity in Northern China. Water 2021, 13, 1318. https: / / doi.org/10.3390/w13091318

Academic Editor: Elias Dimitriou

Received: 7 April 2021

Accepted: 5 May 2021

Published: 9 May 2021

Publisher's Note: MDPI stays neutral with regard to jurisdictional claims in published maps and institutional affiliations.

Copyright: (c) 2021 by the authors. Licensee MDPI, Basel, Switzerland. This article is an open access article distributed under the terms and conditions of the Creative Commons Attribution (CC BY) license (https:// creativecommons.org/licenses/by/ $4.0 /)$.
State Key Laboratory of Water Environment Simulation, School of Environment, Beijing Normal University, No. 19, Xinjiekouwai Street, Haidian District, Beijing 100875, China; meng@bnu.edu.cn (C.M.); 201531180002@bnu.edu.cn (R.C.); Zhousiyang@mail.bnu.edu.cn (S.Z.)

* Correspondence: weili@bnu.edu.cn; Tel.: +86-10-6220-2877

\begin{abstract}
Water resource allocation aimed at sustainable watershed development suffers from prominent challenges such as water pollution and scarcity, especially in water-deprived regions. Based on analysis of water quality, use, and sectoral demands during the planning period in the Fenhe River Basin, an improved inexact two-stage stochastic programming model with downside risk control was built for optimal resource allocations for the four primary sectors (industry, domestic use, agriculture, and the environment) in the basin. The principal constraints are river water quality and available water resources under the three hydrological scenarios (low, medium, and high). The results show that industrial, domestic, and agricultural water use in the middle and lower reaches were significantly reduced by requiring improved water quality; agriculture suffered the greatest water shortage and risk. As the level of risk control improved, the comprehensive watershed benefits and agricultural risks were gradually reduced. Improving water reuse significantly reduces the risk and increases the benefits. The model can effectively manage rational water allocations under the dual constraints of water quality and quantity, meanwhile alleviating water competition caused by different water benefits to provide support for coordinating the improvement of water quality and socio-economic development in the basin.
\end{abstract}

Keywords: water resource allocation; dual constraints; water pollution; cross-sector competition; two-stage stochastic programming; downside risk control

\section{Introduction}

Water resources play an essential role in human survival, sustainable socio-economic development, and ecosystem and environmental security [1]. However, with the advance of urbanization and industrialization, water pollution and water shortages have become great challenges in northern China and worldwide [2-4]. Excessive water resource exploitation, relatively inefficient utilization, increasing wastewater discharge, and discounting of environmental water demand have reduced river flows, lowered groundwater levels, and exacerbated the deterioration of the quality of the water environment [5]. The shortage of water resources is especially pronounced in water-deprived regions and has become a critical constraint for watershed socioeconomic development [6,7]. Water pollution is the most pressing issue in China, which experiences exacerbated water shortages and cross-sectoral water competition (e.g., the environment, industry, domestic and agriculture). High-quality development based on protection of the water environment and rational water resource utilization is a developmental priority for a regional social economy. Therefore, optimal regulation of water resource consumption and regional and sectoral allocations for synergetic development between the social economy and the environment are particularly significant. 
Studies on the coordinated relationship between the water environment and socioeconomic development in river watersheds indicate that adjusting the industrial structure and technological progress is necessary to improve water-use efficiency and to achieve harmonious economical and societal development [8]. The optimal allocation of water resources is one of the most effective resolutions for addressing water pollution, water shortages, and rising water demand $[9,10]$. The many uncertainties in the water environment system include stochasticity of available water resources caused by climate change [11-13] uncertainties regarding plans and policies, and the complexity of interconnected processes between the social economy and the environment (e.g., water utilization, wastewater treatment, recycling, discharge, and water quality). These uncertainties generate enormous challenges for water resources and water quality management.

Several optimization approaches have been developed for water resource allocation and water quality management with uncertainties [14-16]. The inexact two-stage stochastic programming (ITSP) model integrates interval-parameter programming (IPP) and two-stage stochastic programming (TSP) and addresses uncertainties expressed as probability distributions and as discrete intervals. ITSP has been widely applied to address different forms of multiple uncertainties in water resource allocation and water quality management [17-24]. However, the ITSP model does not consider the variability of the second-stage cost or benefit, only its expected value; this leads to an unbalanced allocation pattern. For example, managed water resources are primarily allocated to regions and sectors with higher water benefits, which may lead to insufficient water supply for regions or sectors with lower benefits [25], and the subjective will of decision makers such as changes of development priority, pursuit of the largest economy benefits or balanced development, and enhancement of environment protection, which all significantly influence optimal strategies. Moreover, most studies do not sufficiently consider watersheds with severe water pollution and water scarcity problems, such as the Fenhe River basin in Shanxi province, northern China. The Fenhe River Basin has a semi-humid climate and experiences common water resource shortages, with a water resource per capita of $378 \mathrm{~m}^{3}$, $18 \%$ of the national average. The utilization rate of water resources has long exceeded $70 \%$, leading to serious water conflicts between the social economy and the environment, which means unbalanced water utilization and necessary regulation (e.g., optimization of water resource allocation, improvement of water efficiency, pollutants reduction), and it is impossible to meet the water demands of each sector at the same time presently. The Fenhe River increasingly suffers from environmental problems, such as serious water pollution and ecological damage; and more than $80 \%$ of the river segments do not meet national water quality targets, which exacerbates watershed water shortages and cross-sectoral water competition. Thus, an effective approach for dealing with severe environmental problems and water shortages in river basins must be explored.

Previous studies have found that the downside risk method is an advantageous measure that balances benefits and resource allocation by minimizing the risks for all parties under certain conditions [26]. The downside risk method can integrate a programming model with a scenario-based description of problem data and generates a series of solutions that help decision-makers quantitatively evaluate trade-offs between the system economy and stability [27-30]. Xie and Huang [25] developed and applied an inexact two-stage stochastic downside risk-aversion programming (ITSDP) model to support regional water resource allocation and water quality management problems with uncertainties in a hypothetical case with one municipal, three industrial, and two agricultural sectors. The ITSDP model effectively addressed water competition and balance system benefits through downside risk control.

This study aims to improve the ITSDP model to address water conflicts and rational water resource allocation under the dual constraints of water pollution and water scarcity in the Fenhe River Basin. The model combines water benefits with water environment protection, which resolves the water resource conflict between the environment and production sectors. Water resource utilization and pollutant emissions must meet water quality 
standards, and water resource allocation strategies for different watershed divisions and sectors should be optimized to ensure coordinated development. Figure 1 presents the general framework of the ITSDP model for optimal water management in the Fenhe River Basin with uncertainties for integrating water quality management and water resource allocation. The application of the model could help optimize and regulate regional water resource allocation strategies and pollutant discharge levels under the constraints of water quality and resource security. Furthermore, the results could be useful for supporting watershed decision-makers to establish and to improve water-based industrial structures and layouts.

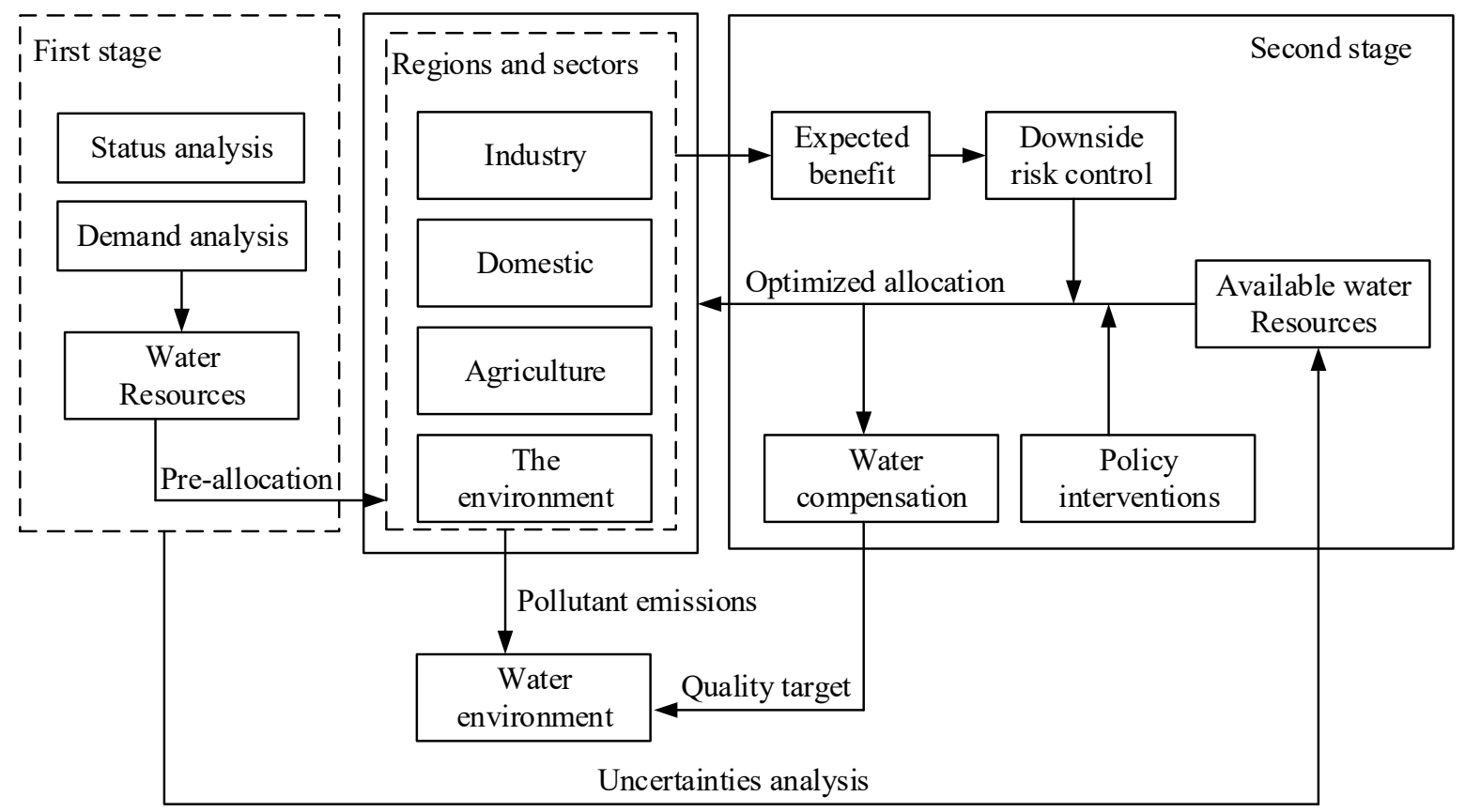

Figure 1. Framework for the inexact downside risk control and two-stage stochastic programming model.

\section{The Study Area}

The Fenhe River $\left(110^{\circ} 30^{\prime} \mathrm{E}-113^{\circ} 32^{\prime} \mathrm{E}, 35^{\circ} 20^{\prime} \mathrm{N}-39^{\circ} 00^{\prime} \mathrm{N}\right)$ is located in central and southeastern Shanxi Province, China. The river originates in Ningwu County and flows through six cities: Xinzhou, Taiyuan, Jinzhong, Lvliang, Linfen, and Yuncheng, before flowing into the Yellow River in Hejin County.

The Fenhe River is the second largest branch of the Yellow River and the largest river in Shanxi, with a total length of $694 \mathrm{~km}$ and a watershed area of approximately $39,471 \mathrm{~km}^{2}$, which accounts for $25.5 \%$ of the total area of the province. The Fenhe River Basin has a semiarid and semi-humid transitional climate and is located in the mid-latitude continental monsoon zone. The inter-annual variation in rainfall is large, and the distribution is uneven during the year; $70 \%$ of the annual precipitation is concentrated from June to September. The multi-year (1956-2010) average rainfall of the entire basin is $504.8 \mathrm{~mm}$ (with a ten-year decreasing trend), and the water surface evaporation is $900-1200 \mathrm{~mm}$. The total available water resources (from 1956-2010) of the Fenhe River Basin are 2.656 billion $\mathrm{m}^{3}$, of which surface water and groundwater account for 1.482 and 1.885 billion $\mathrm{m}^{3}$, respectively.

The Fenhe River Basin occupies a pivotal position in the social and economic development of Shanxi, which is highly urbanized and agriculturally developed. The Basin contains $40.83 \%, 44.02 \%$, and $64 \%$ of provincial population, gross domestic product, and agricultural output, respectively. However, the Fenhe River Basin is a relatively severely water-deprived region and with overexploited water resources. The utilization rate of surface water development is $75.91 \%$, and the average utilization rate of groundwater development reaches $85 \%$. Moreover, due to over-exploitation, uneven allocation, and low 
utilization efficiency of water resources, excessive pollutant discharge (especially ammonia nitrogen) has caused serious environmental problems in the Fenhe River. Therefore, developing effective approaches to coordinate and optimize the distribution of water resources and to improve the quality of the water environment is imperative for achieving sustainable and high-quality development in the basin.

In this study, the scope of the Fenhe River Basin was determined using the hydrological analysis module of ARCGIS and includes the upstream, midstream, and downstream areas of the river and 16 units with the corresponding water quality sections (Figure 2).

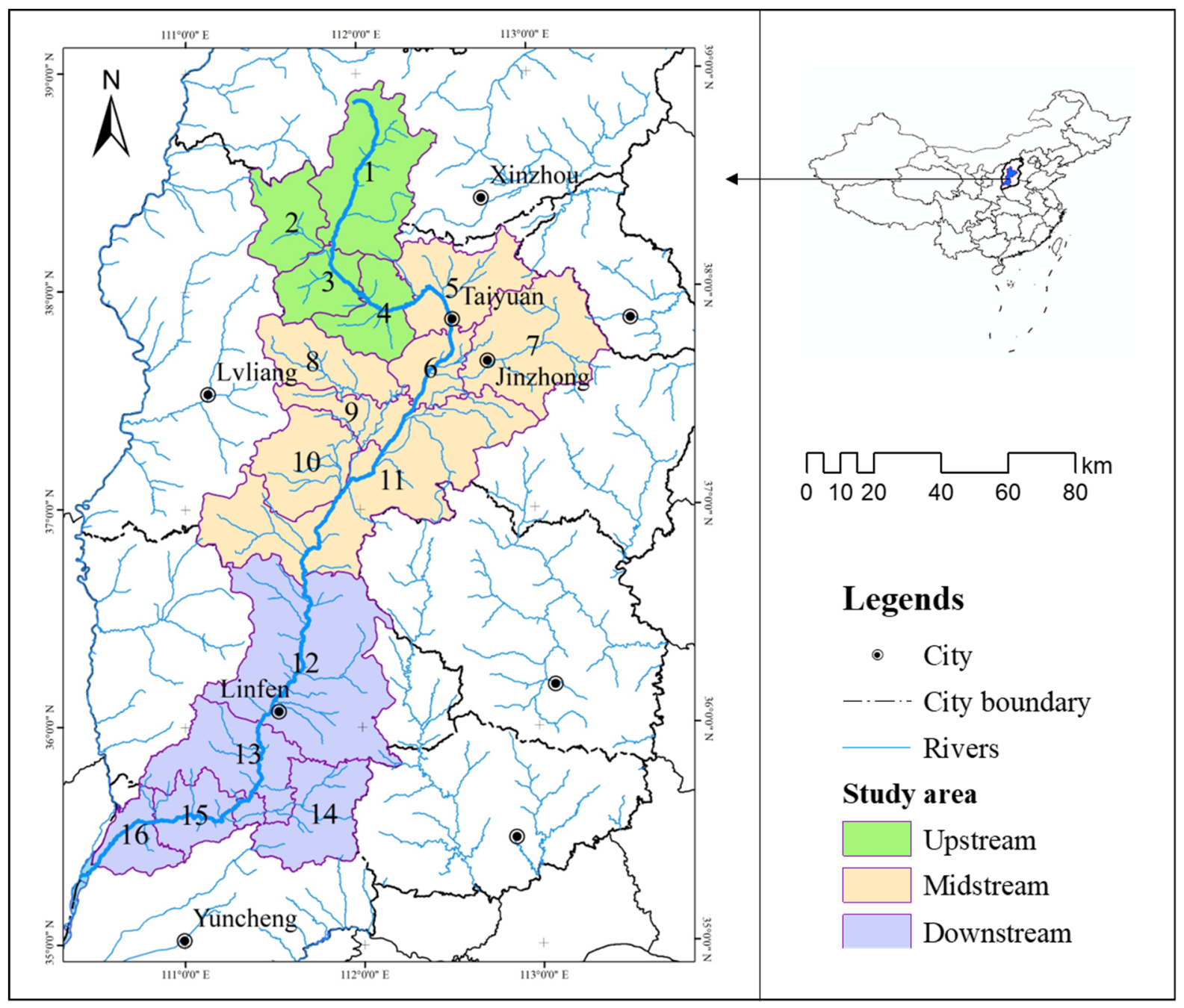

Figure 2. Geographical position and study area of the Fenhe River Basin.

\section{Method and Data}

\subsection{Model Development}

This study considers long-run programming. The planning horizon covers 15 years divided into five-year periods (i.e., 2019-2023, 2024-2028, and 2029-2033) and considers three hydrological scenarios (low, medium, and high) that reflect different available water resources and water environmental capacities. The ITSDP model for integrating water resource allocation and water quality management in the Fenhe River Basin can be formulated as follows:

$$
\max f^{ \pm}=f_{1}^{ \pm}-f_{2}^{ \pm}-f_{3}^{ \pm}-f_{4}^{ \pm}-f_{5}^{ \pm}-f_{6}^{ \pm}
$$


where $f^{ \pm}$is the total benefit of water resource utilization in the basin $\left(10^{4} \mathrm{CNY}\right)$ over the planning period.

(1) Water benefits:

$$
f_{1}^{ \pm}=\sum_{i=1}^{16} \sum_{k=1}^{4} \sum_{t=1}^{3} L_{t} \cdot U N B_{i k t}^{ \pm} \cdot\left(I A W_{i k t}^{ \pm}+\sum_{h=1}^{3} p_{h} \cdot R W_{i k t h}^{ \pm}\right)
$$

where $i$ denotes the control unit; $k$ denotes the water sector ( $k=1$ for industry, $k=2$ for domestic, $k=3$ for agriculture, and $k=4$ for the environment); $t$ denotes different periods in the planning horizon ( $t=1$ is 2019-2023, $t=2$ is 2024-2028, and $t=3$ is 2029-2033); $L_{t}$ denotes the length of period $t$, and the values are fixed at 5 years; $U N B_{i k t}^{ \pm}$represents the water-use benefit for each sector $\left(10^{4} \mathrm{CNY} / 10^{4} \mathrm{~m}^{3}\right) ; I A W_{i k t}^{ \pm}$represents the pre-allocation of water resources for each sector $\left(10^{4} \mathrm{~m}^{3} /\right.$ year $)$; and $R W_{j k t}^{ \pm}$represents reused water resources for each sector $\left(10^{4} \mathrm{~m}^{3} /\right.$ year $)$.

(2) Water shortage penalties:

$$
f_{2}^{ \pm}=\sum_{i=1}^{16} \sum_{k=1}^{4} \sum_{t=1}^{3} \sum_{h=1}^{3} L_{t} \cdot p_{h} \cdot P N B_{i k t}^{ \pm} \cdot D I A W_{i k t h}^{ \pm}
$$

where $h$ denotes various water resource scenarios in each period $(h=1,2$, and 3 for low, medium, and high levels, respectively), $p_{h}$ denotes the occurrence probability of scenario $h, P N B_{j k t}^{ \pm}$represents the reduction of net benefit per unit of water resource not delivered $\left(10^{4} \mathrm{RMB} / 10^{4} \mathrm{~m}^{3}\right)$, and $D I A W_{i k t h}^{ \pm}$represents the allocation deficit of water resources for each sector $\left(10^{4} \mathrm{~m}^{3} /\right.$ year $)$.

(3) Water supply cost:

$$
\begin{aligned}
f_{3}^{ \pm} & =\sum_{i=1}^{16} \sum_{k=1}^{4} \sum_{t=1}^{3} L_{t} \cdot\left(I A W_{i k t}^{ \pm}-\sum_{h=1}^{3} p_{h} \cdot D I A W_{i k t h}^{ \pm}\right) \cdot C W_{i k t}^{ \pm} \\
& +\sum_{i=1}^{16} \sum_{k=1}^{4} \sum_{t=1}^{4} \sum_{h=1}^{3} p_{h} \cdot L_{t} \cdot R W_{i k t h}^{ \pm} \cdot C R W_{i k t}^{ \pm}
\end{aligned}
$$

where $C W_{j k t}^{ \pm}$represents the cost of the water supply in each sector $\left(10^{4} \mathrm{RMB} / 10^{4} \mathrm{~m}^{3}\right)$, and $C R W_{j k t}^{ \pm}$is the cost of reused water supply for each sector $\left(10^{4} \mathrm{RMB} / 10^{4} \mathrm{~m}^{3}\right)$.

(4) Wastewater treatment cost:

$$
f_{4}^{ \pm}=\sum_{i=1}^{16} \sum_{k=1}^{4} \sum_{t=1}^{3} L_{t} \cdot\left(I A W_{i k t}^{ \pm}-\sum_{h=1}^{3} p_{h} \cdot D I A W_{i k t h}^{ \pm}\right) \cdot \alpha_{i k t}^{ \pm} \cdot\left(C W W_{i k t}^{ \pm}+\xi_{i k t}^{ \pm} \cdot C R W T_{i k t}^{ \pm}\right)
$$

where $C W W_{j k t}^{ \pm}$represents the costs of wastewater treatment $\left(10^{4} \mathrm{CNY} / 10^{4} \mathrm{~m}^{3}\right)$, and $C R W T_{j k t}^{ \pm}$denotes the costs of wastewater reclamation $\left(10^{4} \mathrm{CNY} / 10^{4} \mathrm{~m}^{3}\right)$.

(5) Water-compensation costs:

$$
f_{5}^{ \pm}=\sum_{i=1}^{16} \sum_{t=1}^{3} \sum_{h=1}^{3} L_{t} \cdot p_{h} \cdot G W_{i t h}^{ \pm} \cdot C E W_{i t}^{ \pm}
$$

where $G W_{i t h}^{ \pm}$is the environmental water compensation (i.e., ecological water flow must meet water quality targets); high values of $G W_{i t h}^{ \pm}$denote less production water; and $C E W_{i t}^{ \pm}$ is the cost of water compensation.

(6) Downside risk constraints:

$$
f_{6}^{ \pm}=\omega \cdot \sum_{i=1}^{16} \sum_{k=1}^{4} \sum_{t=1}^{3} D R i s k_{i k t}^{ \pm}
$$


where $\omega$ represents the risk level; DRisk ${ }_{i k t}^{ \pm}$is the downside risk of each sector.

Constraints:

(1) Water supply constraints:

$$
\begin{gathered}
\sum_{k=1}^{4}\left(I A W_{i j k t}^{ \pm}-D I A W_{i j k t h}^{ \pm}\right) \leq A W Q_{i t}^{ \pm} ; \forall i, t, h \\
\sum_{i=1}^{16} \sum_{k=1}^{4}\left(I A W_{i k t}^{ \pm}-D I A W_{i k t h}^{ \pm}\right)+G W_{i t h}^{ \pm} \leq T A W Q_{t}^{ \pm} ; \forall t, h \\
D I A W_{i k t h}^{ \pm} \leq I A W_{i k t}^{ \pm} ; \forall i, k, t, h
\end{gathered}
$$

where $A W Q_{i t}^{ \pm}$denotes available water resources $\left(10^{4} \mathrm{~m}^{3} /\right.$ year $)$.

(2) Water sector demand constraints:

$$
\begin{aligned}
& \left(I A W_{i k t}^{ \pm}-D I A W_{i k t h}^{ \pm}\right)+R W_{i k t h}^{ \pm} \geq W D_{\text {minikt }}^{ \pm} ; \forall i, k, t, h \\
& \left(I A W_{i k t}^{ \pm}-D I A W_{i k t h}^{ \pm}\right)+R W_{i k t h}^{ \pm} \leq W D_{\text {maxikt }}^{ \pm} ; \forall i, k, t, h
\end{aligned}
$$

where $W D_{\text {minikt }}^{ \pm}$represents the minimum water resources requirement, and $W D_{\text {maxikt }}^{ \pm}$ represents the maximum water resources requirement $\left(10^{4} \mathrm{~m}^{3} /\right.$ year $)$.

(3) Regional wastewater treatment capacity constraints:

$$
\sum_{j=1}^{3}\left(I A W_{i j k t}^{ \pm}-D I A W_{i j k t h}^{ \pm}\right) \cdot \alpha_{i k t}^{ \pm} \leq A T W_{i k t}^{ \pm}, \forall i, t, h, k=1,2
$$

where $\alpha_{i k t}$ is the wastewater emission coefficient, and $A T W_{i k t}^{ \pm}$represents the wastewater treatment capacity ( $10^{4}$ tons).

(4) Regional wastewater reuse capacity constraints:

$$
\left(I A W_{i k t}^{ \pm}-D I A W_{i k t h}^{ \pm}\right) \cdot \alpha_{i k t}^{ \pm} \cdot \xi_{i k t}^{ \pm} \geq \sum_{k=1}^{4} R W_{i k t h}^{ \pm}, \forall i, t, h
$$

where $\tilde{\xi}_{j k t}$ is the wastewater reuse rate.

(5) Constraints for total water pollutant emissions:

$$
\sum_{k=1}^{3} \sum_{j=1}^{3}\left(I A W_{i j k t}^{ \pm}-D I A W_{i j k t h}^{ \pm}\right) \cdot \alpha_{i k t}^{ \pm} \cdot\left(1-\xi_{i k t}^{ \pm}\right) \cdot E C_{k r t}^{ \pm} \leq T E D_{i r t}^{ \pm}, \forall i, r, t, h
$$

where $r$ is the controlled water pollutant $(r=1$ for chemical oxygen demand, $r=2$ for ammonia nitrogen $\left.\left(\mathrm{NH}_{4}-\mathrm{N}\right)\right), E C_{i k r t}^{ \pm}$represents the concentration of pollutants after wastewater treatment $(\mathrm{mg} / \mathrm{L})$, and $T E D_{i r t}^{ \pm}$represents the total amount of pollutant (tons).

(6) Water environment carrying capacity constraints:

$$
\begin{aligned}
& \sum_{k=1}^{3} \sum_{j=1}^{3}\left(I A W_{i j k t}^{ \pm}-D I A W_{i j k t h}^{ \pm}\right) \cdot \alpha_{i k t}^{ \pm} \cdot\left(1-\xi_{i k t}^{ \pm}\right) \cdot E C_{k r t}^{ \pm} \cdot I D R_{k r t} \\
& -\left(C S_{i r t}^{ \pm}-C 0_{i r t}^{ \pm}\right) \cdot G W_{i t h}^{ \pm} \leq A L D_{i r t h}^{ \pm}, \forall i, r, t, h
\end{aligned}
$$

where $I D R_{k r t}$ represents the river load ratio of different pollutants, and $A L D_{i r t h}^{ \pm}$is the environmental capacity (tons) of different pollutants.

(7) Downside risk 


$$
\begin{aligned}
& P R W_{i t h}^{ \pm}=L_{t} \cdot\left\{\begin{array}{l}
\sum_{k=1}^{4} U N B_{i k t}^{ \pm} \cdot\left(I A W_{i k t}^{ \pm}+R W_{i k t h}^{ \pm}\right)-P N B_{i k t}^{ \pm} \cdot D I A W_{i k t h}^{ \pm} \\
-\sum_{k=1}^{4}\left[\left(I A W_{i k t}^{ \pm}-D I A W_{i k t h}^{ \pm}\right) \cdot C W_{i k t}^{ \pm}+R W_{i k t h}^{ \pm} \cdot C R W_{i k t}^{ \pm}\right] \\
-\sum_{k=1}^{4}\left(I A W_{i k t}^{ \pm}-D I A W_{i k t h}^{ \pm}\right) \cdot\left(\alpha_{i k t}^{ \pm} \cdot C W W_{i k t}^{ \pm}+\alpha_{i k t}^{ \pm} \cdot \xi_{i k t}^{ \pm} \cdot C R W T_{i k t}^{ \pm}\right) \\
-G W_{i t h}^{ \pm} \cdot C E W_{i t}^{ \pm}
\end{array}\right\}, \forall i, t, h \\
& \text { Delta }_{i t h}^{ \pm}=\left\{\begin{array}{ll}
\Omega_{i t}^{ \pm}-P R W_{i t h}^{ \pm} & P R W_{i t h}^{ \pm}<\Omega_{i t}^{ \pm} \\
0, & P R W_{i t h}^{ \pm}>\Omega_{i t}^{ \pm}
\end{array}, \forall i, t, h\right. \\
& \operatorname{DRisk}_{i t}^{ \pm}=\sum_{h=1}^{3} p_{h} \cdot \operatorname{Delta}_{i t h}^{ \pm}, \forall i, t
\end{aligned}
$$

where $P R W_{i t h}^{ \pm}$represents the actual benefit, $\Omega_{i t}^{ \pm}$represents the expected regional benefit, Delt $a_{i t h}^{ \pm}$represents the positive deviation from the expected benefit, and DRisk $k_{i t}^{ \pm}$represents the downside risk.

(8) Others:

$$
D I A W_{i k t h}^{ \pm}, R W_{i k t h}^{ \pm} \geq 0
$$

The objective is to maximize the total benefits in the river basin; including those of pre-allocated water resource sectors; penalties for undelivered allocations; and the costs of water supply, wastewater treatment, wastewater reclamation, and purification of excess pollutants. The constraints are for the relationships between decision values and water quality requirements, including available water resources, regional total amount controlled, environmental water carrying capacity, and downside risks.

Using an interactive algorithm, the ITSDP model can be transformed into two deterministic sub-models that correspond to the lower and upper bounds of the desired objective function value. The DIAW $W_{i k t h}^{-}, R W_{i k t h^{\prime}}^{+} G W_{i t h^{\prime}}^{-} D R i s k_{i k t}^{-}$and DIAW $W_{i k t h}^{+}, R W_{i k t h}^{-}$ $G W_{i t h}^{+}, D R i s k_{i k t}^{+}$sub-models are solved to form the final ITSDP model solution: [DIAW $W_{i k t h}^{-}$ $\left.D I A W_{i k t h}^{+}\right],\left[R W_{i k t h}^{-}, R W_{i k t h}^{+}\right],\left[G W_{i t h^{\prime}}^{-} G W_{i t h}^{+}\right]$, and [DRisk $\left.{ }_{i k t}^{-}, D R i s k_{i k t}^{+}\right]$.

\subsection{Datasets}

Table 1 lists the available water resources in the upper, middle, and lower reaches of the Fenhe River, including surface water, groundwater, and transferred water from the Yellow River. These were calculated based on water resource evaluation results (1956-2010) combined with regional water resource planning and management policies.

Table 1. Available water resources in the Fenhe River Basin $\left(10^{4} \mathrm{~m}^{3} /\right.$ year $)$.

\begin{tabular}{ccccc}
\hline \multirow{2}{*}{ Water Resources } & Periods & \multicolumn{3}{c}{ Scenarios } \\
\cline { 3 - 5 } & & $\mathbf{h}=\mathbf{1}$ & $\mathbf{h}=\mathbf{2}$ & $\mathbf{h}=\mathbf{3}$ \\
\hline \multirow{3}{*}{ Surface water } & $\mathrm{t}=1$ & {$[14,716,18,395]$} & {$[22,640,28,300]$} & {$[41,163,51,454]$} \\
& $\mathrm{t}=2$ & {$[14,872,18,590]$} & {$[22,880,28,600]$} & {$[41,600,52,000]$} \\
Groundwater & $\mathrm{t}=3$ & {$[15,028,18,785]$} & {$[23,120,28,900]$} & {$[42,036,52,545]$} \\
& $\mathrm{t}=1$ & {$[2560,3200]$} & {$[2560,3200]$} & {$[2560,3200]$} \\
Transferred water & $\mathrm{t}=2$ & {$[2560,3200]$} & {$[2560,3200]$} & {$[2560,3200]$} \\
& $\mathrm{t}=3$ & {$[2560,3200]$} & {$[2560,3200]$} & {$[2560,3200]$} \\
& $\mathrm{t}=1$ & {$[1800,2250]$} & {$[1800,2250]$} & {$[1800,2250]$} \\
Surface water & $\mathrm{t}=2$ & {$[2400,3000]$} & {$[2400,3000]$} & {$[2400,3000]$} \\
& $\mathrm{t}=3$ & {$[3000,3750]$} & {$[3000,3750]$} & {$[3000,3750]$} \\
& $\mathrm{t}=1$ & {$[38,480,48,100]$} & {$[59,200,74,000]$} & {$[107,636,134,545]$} \\
& $\mathrm{t}=2$ & {$[39,988,49,985]$} & {$[61,520,76,900]$} & {$[111,854,139,818]$} \\
& $\mathrm{t}=3$ & {$[41,496,51,870]$} & {$[63,840,79,800]$} & {$[116,072,145,090]$} \\
\hline
\end{tabular}


Table 1. Cont.

\begin{tabular}{ccccc}
\hline \multirow{2}{*}{ Water Resources } & Periods & \multicolumn{3}{c}{ Scenarios } \\
\cline { 3 - 5 } & & $\mathbf{h}=\mathbf{1}$ & $\mathbf{h}=\mathbf{2}$ & $\mathbf{h}=\mathbf{3}$ \\
\hline \multirow{3}{*}{ Groundwater } & $\mathrm{t}=1$ & {$[49,600,62,000]$} & {$[49,600,62,000]$} & {$[49,600,62,000]$} \\
& $\mathrm{t}=2$ & {$[47,120,58,900]$} & {$[47,120,58,900]$} & {$[47,120,58,900]$} \\
& $\mathrm{t}=3$ & {$[44,640,55,800]$} & {$[44,640,55,800]$} & {$[44,640,55,800]$} \\
Transferred water & $\mathrm{t}=1$ & {$[76,800,96,000]$} & {$[76,800,96,000]$} & {$[76,800,96,000]$} \\
& $\mathrm{t}=2$ & {$[86,400,108,000]$} & {$[86,400,108,000]$} & {$[86,400,108,000]$} \\
\multirow{2}{*}{ Surface water } & $\mathrm{t}=3$ & {$[96,000,120,000]$} & {$[96,000,120,000]$} & {$[96,000,120,000]$} \\
& $\mathrm{t}=1$ & {$[18,096,22,620]$} & {$[27,840,34,800]$} & {$[50,618,63,272]$} \\
Groundwater & $\mathrm{t}=2$ & {$[18,096,22,620]$} & {$[27,840,34,800]$} & {$[50,618,63,272]$} \\
& $\mathrm{t}=3$ & {$[18,096,22,620]$} & {$[27,840,34,800]$} & {$[50,618,63,272]$} \\
& $\mathrm{t}=1$ & {$[24,600,30,750]$} & {$[24,600,30,750]$} & {$[24,600,30,750]$} \\
Transferred water & $\mathrm{t}=2$ & {$[22,880,28,600]$} & {$[22,880,28,600]$} & {$[22,880,28,600]$} \\
& $\mathrm{t}=3$ & {$[21,160,26,450]$} & {$[21,160,26,450]$} & {$[21,160,26,450]$} \\
& $\mathrm{t}=1$ & {$[54,840,68,550]$} & {$[54,840,68,550]$} & {$[54,840,68,550]$} \\
& $\mathrm{t}=2$ & {$[59,920,74,900]$} & {$[59,920,74,900]$} & {$[59,920,74,900]$} \\
& $\mathrm{t}=3$ & {$[65,000,81,250]$} & {$[65,000,81,250]$} & {$[65,000,81,250]$} \\
\hline
\end{tabular}

Table 2 lists the pre-allocation strategies of water resources in the Fenhe River Basin, which were calculated based on the latest regional water resource consumption in each sector and development planning and policy analysis in the river basin. 
Table 2. Initial water resource allocation in the Fenhe River Basin $\left(10^{4} \mathrm{~m}^{3} /\right.$ year $)$.

\begin{tabular}{|c|c|c|c|c|c|c|c|c|c|c|c|c|}
\hline \multirow{3}{*}{ Units } & \multicolumn{12}{|c|}{ Periods and Sectors } \\
\hline & \multicolumn{4}{|c|}{$t=1$} & \multicolumn{4}{|c|}{$t=2$} & \multicolumn{4}{|c|}{$t=3$} \\
\hline & Industry & Domestic & Agriculture & $\begin{array}{l}\text { The Envi- } \\
\text { ronment }\end{array}$ & Industry & Domestic & Agriculture & $\begin{array}{l}\text { The Envi- } \\
\text { ronment }\end{array}$ & Industry & Domestic & Agriculture & $\begin{array}{l}\text { The Envi- } \\
\text { ronment }\end{array}$ \\
\hline Unit1 & {$[196,221]$} & {$[715,869]$} & {$[10,351,10,778]$} & {$[870,937]$} & {$[200,246]$} & {$[698,977]$} & $\begin{array}{l}{[11,234,} \\
12,042]\end{array}$ & {$[1132,1313]$} & {$[204,274]$} & {$[683,1099]$} & $\begin{array}{l}{[11,940} \\
13,175]\end{array}$ & {$[1471,1838]$} \\
\hline Unit2 & {$[181,213]$} & {$[314,377]$} & {$[4623,4817]$} & {$[282,303]$} & {$[179,237]$} & {$[310,423]$} & {$[4584,4918]$} & {$[366,425]$} & {$[177,264]$} & {$[305,474]$} & {$[4568,5047]$} & {$[476,595]$} \\
\hline Unit3 & {$[695,799]$} & {$[267,343]$} & {$[2883,3004]$} & {$[60,64]$} & {$[735,933]$} & {$[258,395]$} & {$[2938,3152]$} & {$[78,90]$} & {$[777,1089]$} & {$[249,457]$} & {$[2931,3238]$} & {$[101,126]$} \\
\hline Unit5 & {$[5356,6947]$} & {$[2844,3646]$} & {$[5650,5886]$} & {$[778,803]$} & {$[4598,7179]$} & {$[2705,4140]$} & {$[5716,6133]$} & {$[1206,1285]$} & {$[3946,7420]$} & {$[2572,4701]$} & {$[5723,6322]$} & {$[1869,2056]$} \\
\hline Unit6 & {$[2104,2738]$} & $\begin{array}{l}{[26,940,} \\
32,755]\end{array}$ & {$[6210,6470]$} & {$[7213,7445]$} & {$[1807,2839]$} & $\begin{array}{l}{[26,015} \\
36,369]\end{array}$ & {$[6131,6578]$} & $\begin{array}{l}{[11,180} \\
11,913]\end{array}$ & {$[1552,2943]$} & $\begin{array}{l}{[25,122,} \\
40,383]\end{array}$ & {$[6214,6865]$} & $\begin{array}{l}{[17,329,} \\
19,061]\end{array}$ \\
\hline Unit7 & {$[898,1023]$} & {$[5213,6336]$} & {$[18,921,19,440]$} & {$[3681,3800]$} & {$[889,1113]$} & {$[5045,7049]$} & $\begin{array}{l}{[19,946,} \\
20,893]\end{array}$ & {$[5707,6081]$} & {$[881,1210]$} & {$[4882,7841]$} & $\begin{array}{l}{[21,356,} \\
22,806]\end{array}$ & {$[8845,9729]$} \\
\hline Unit8 & {$[905,1050]$} & {$[387,476]$} & {$[1951,2033]$} & {$[425,438]$} & {$[885,1143]$} & {$[374,534]$} & {$[1942,2083]$} & {$[658,702]$} & {$[866,1244]$} & {$[361,598]$} & {$[1932,2134]$} & {$[1021,1123]$} \\
\hline Unit9 & {$[553,657]$} & {$[583,738]$} & {$[1361,1418]$} & {$[650,670]$} & {$[558,749]$} & {$[558,834]$} & {$[1340,1438]$} & {$[1007,1073]$} & {$[562,855]$} & {$[533,943]$} & {$[1340,1481]$} & {$[1561,1717]$} \\
\hline Unit10 & {$[3751,4497]$} & {$[2072,2587]$} & {$[15,084,15,716]$} & {$[2298,2372]$} & {$[3758,5129]$} & {$[1986,2906]$} & $\begin{array}{l}{[14,852} \\
15,936]\end{array}$ & {$[3562,3796]$} & {$[3766,5851]$} & {$[1903,3264]$} & $\begin{array}{l}{[14,853,} \\
16,412]\end{array}$ & {$[5522,6074]$} \\
\hline Unit12 & {$[3882,4532]$} & {$[5591,7453]$} & {$[34,208,35,393]$} & {$[3415,3605]$} & {$[3868,5044]$} & {$[5189,8492]$} & $\begin{array}{l}{[35,295} \\
37,418]\end{array}$ & {$[6148,6850]$} & {$[3854,5615]$} & {$[4815,9676]$} & $\begin{array}{l}{[36,034} \\
39,142]\end{array}$ & $\begin{array}{l}{[11,067,} \\
13,016]\end{array}$ \\
\hline Unit13 & {$[3403,3842]$} & {$[1003,1302]$} & {$[24,856,25,718]$} & {$[603,636]$} & {$[3474,4276]$} & {$[941,1473]$} & $\begin{array}{l}{[25,824} \\
27,377]\end{array}$ & {$[1085,1209]$} & {$[3546,4759]$} & {$[883,1667]$} & $\begin{array}{l}{[26,274,} \\
28,540]\end{array}$ & [1954, 2298] \\
\hline Unit14 & {$[502,567]$} & {$[1912,2355]$} & {$[14,062,14,550]$} & {$[1119,1182]$} & {$[500,616]$} & {$[1828,2615]$} & $\begin{array}{l}{[14,209,} \\
15,064]\end{array}$ & {$[2015,2245]$} & {$[499,670]$} & {$[1748,2903]$} & $\begin{array}{l}{[14,659} \\
15,923]\end{array}$ & {$[3628,4267]$} \\
\hline Unit15 & {$[1920,2207]$} & {$[715,978]$} & {$[15,135,15,655]$} & {$[137,144]$} & {$[1983,2517]$} & {$[656,1123]$} & $\begin{array}{l}{[16,235} \\
17,204]\end{array}$ & {$[247,275]$} & {$[2048,2871]$} & {$[602,1289]$} & $\begin{array}{l}{[17,232,} \\
18,706]\end{array}$ & {$[444,523]$} \\
\hline Unit16 & {$[6176,7469]$} & {$[1624,2082]$} & {$[18,600,19,239]$} & {$[301,318]$} & {$[6293,8718]$} & {$[1524,2334]$} & $\begin{array}{l}{[20,021} \\
21,215]\end{array}$ & {$[543,605]$} & $\begin{array}{r}{[6412} \\
10,175]\end{array}$ & {$[1431,2616]$} & $\begin{array}{l}{[21,213,} \\
23,028]\end{array}$ & {$[978,1150]$} \\
\hline
\end{tabular}




\section{Results and Discussions}

\subsection{Downside Risks}

In this study, the optimal results were obtained without the downside risk control constraints through the ITSP model for an $\omega$ value fixed at 0 . Further, values of 5, 15, 30 , and 50 were selected to reflect different risk levels and corresponding changes in optimization strategies.

Table 3 lists the benefits of water resource utilization at different risk levels in the Fenhe River Basin. The table shows that the benefits decrease slightly as the $\omega$ values increase, which is similar to previous studies [25]. For example, in period 1, the benefits are CNY [5.97, 6.74], [5.97, 6.73], [5.95, 6.73], [5.92, 6.70], and [5.89, 6.62] $\times 10^{6}$ million. The weak changes might be caused by more pre-allocation of water resources and to relatively conservative expected benefit to some sectors or units in this study. The risks also decrease gradually. For example, in period 1, the risks in the entire basin are CNY [5.78, 12.79], [5.53, 11.99], [5.45, 11.72], [5.35, 11.65], and [5.12, 11.56] $\times 10^{4}$ million for $\omega$ of $0,5,15,30$, and 50 , respectively. A higher $\omega$ value indicates a stronger risk control requirement. As the $\omega$ values increase, the ITSDP model optimizes the water resource allocation strategies for units and sectors based on factors, such as water efficiencies, pollutant emission intensities, and regional industry structures. Units and sectors have significantly different risks. Risks in the upstream area of the Fenhe River Basin (units 1-4) are significantly lower than in the other areas; the industrial and domestic risk values in these units are zero in periods 1 and 2, except for low risks for industry (in period 3) and agriculture. These results indicate sufficient water resources and excellent environmental status in the upstream area. Risks primarily appeared in the downstream areas (units 12-16), with values of CNY [1.94, 5.28], $[1.81,4.54],[1.81,4.54],[1.73,4.47]$, and $[1.49,4.42] \times 10^{4}$ million under different risk levels.

Table 3. Benefits of water resource utilization at different risk levels in the Fenhe River Basin (CNY $10^{6}$ million).

\begin{tabular}{cccc}
\hline \multirow{2}{*}{ Risk Levels } & \multicolumn{3}{c}{ Periods } \\
\cline { 2 - 4 } & $\mathbf{t}=\mathbf{1}$ & $\mathbf{t}=\mathbf{2}$ & $\mathbf{t}=\mathbf{3}$ \\
\hline$\omega=0$ & {$[5.97,6.74]$} & {$[8.46,10.53]$} & {$[10.96,15.49]$} \\
$\omega=5$ & {$[5.97,6.73]$} & {$[8.45,10.52]$} & {$[10.88,15.42]$} \\
$\omega=10$ & {$[5.95,6.73]$} & {$[8.41,10.52]$} & {$[10.82,15.23]$} \\
$\omega=20$ & {$[5.92,6.70]$} & {$[8.39,10.47]$} & {$[10.72,14.98]$} \\
$\omega=30$ & {$[5.89,6.62]$} & {$[8.32,10.37]$} & {$[10.71,14.83]$} \\
\hline
\end{tabular}

Risks show similar changes by sector (Figure 3). For example, in period 3, industry and agriculture risks were CNY [25.34, 56.17], [20.25, 56], [20.16, 49.02], [19.96, 47.19], and [19.95, 47.45] $\times 10^{4}$ million and CNY [7.62, 15.84], [6.95, 15.72], [6.02, 15.62], [5.53, 15.56], and $[5.23,15.56] \times 10^{4}$ million for $\omega$ values of $0,5,15,30$ and 50, respectively; this showed a downward trend as risk levels increased. However, domestic risks were CNY [14.08, 85.33], [13.14, 80.68], [12.46, 87.11], [11.86, 93.21], and [11.85, 93.79] $\times 10^{4}$ million with an increasing upper bound for $\omega$ values of 15,30 , and 50 , respectively. The upper bound of the risks corresponds to the lower bound of water resources, and the ITSDP model aims to maximize the total benefit by transferring water resources to higher benefit sectors and units to decrease the total risk in a water-deprived scenario. Taking the downstream area under these three risk control levels for further analysis revealed that for an increase in $\omega$ value from 15 to 30 , the upper bounds of the total industry, domestic, and agriculture risk values change from CNY 47.38, 53.46, $7.27 \times 10^{4}$ million to CNY 45.55, 57.97, and $7.22 \times 10^{4}$ million, respectively; the values in different units change from CNY 42.26, 17.04, $11.52,9.39$, and $27.9 \times 10^{4}$ million to CNY 42.73, 17.66, 11.97, 11.59, and $26.78 \times 10^{4}$ million, reflecting reallocations between units and sectors. However, the upper bound of the total risk would be CNY 108.12, 110.73, and $111.11 \times 10^{4}$ million, showing an upward trend as the risk control level increased. The downstream areas were set as relatively independent 
areas in this part of the study; therefore, opposite results correspond to the methodology of the ITSDP model. Further analysis of optimal water resource allocations reveals an increase in ecological water supply; thus, pollutant emissions exceed the water environmental carrying capacity. The supply of additional water resources to purify water quality reduces water available for production and increases risks. The strong water quality constraint plays a decisive role in the optimal allocation of water resources in this study.
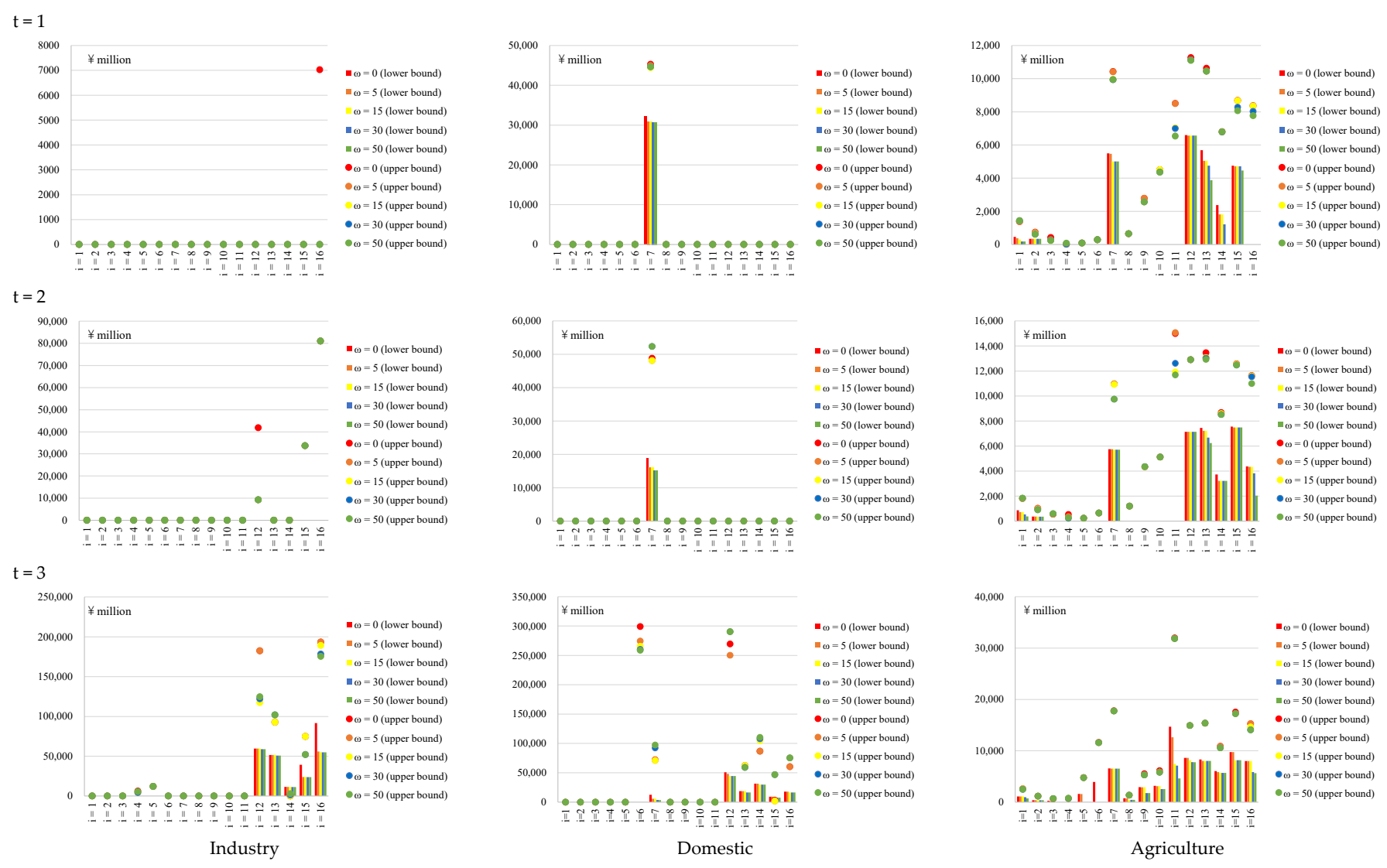

Figure 3. Downside risks in the Fenhe River Basin at different risk levels.

\subsection{Water Resource Allocation}

Table 4 lists the ecological water supplied for purifying pollutants in the Fenhe River Basin, and Figure 4 shows the variation tendencies. As the risk level increases, the ecological water supplies decrease slightly; for example, in period 3 under scenario 3 , the amounts of ecological water were [68,971.33, 71,230.94], [65,884.16, 70,614.86], [62,650.05, 67,134.40], $[61,506.59,66,346.23]$, and $[61,444.22,66,287.66] \times 10^{4} \mathrm{~m}^{3}$, with significant variations by period and scenario. The amount of supplied ecological water decreased slightly from period 1 to period 2 and increased significantly in period 3. For example, the amounts under scenario 1 were $[45,908.44,58,926.27]$, [41,948.42, 56,463.97] and [53,467.22, 72,236.61] $\times 10^{4} \mathrm{~m}^{3}$ in the three periods with an $\omega$ value of 15; the decrease in period 2 is influenced by improved water use efficiency and emission standards, and the increase in period 3 is primarily due to incoordination between higher water quality requirements and conservative of technology improvement forecasts. Ecological water supply from scenario 1 to 3 in periods 1 and 2 decreases significantly, primarily because more available water resources translate to higher environmental carrying capacities. However, in period 3, increased ecological water supply in scenario 2 shows that more water resources should be first allocated to production sectors to meet the expected benefit targets as available water resources increase; this premise is based on the need to reach the established water quality standard. 
Table 4. Ecological water supply at different risk control levels in the Fenhe River Basin $\left(10^{4} \mathrm{~m}^{3}\right)$.

\begin{tabular}{|c|c|c|c|c|c|c|}
\hline \multirow{2}{*}{ Periods } & \multirow{2}{*}{ Scenarios } & \multicolumn{5}{|c|}{ Risk Control Levels } \\
\hline & & $\omega=0$ & $\omega=5$ & $\omega=15$ & $\omega=30$ & $\omega=50$ \\
\hline \multirow{3}{*}{$\mathrm{t}=1$} & $\mathrm{~h}=1$ & $\begin{array}{l}{[47,269.97,} \\
58,799.61]\end{array}$ & $\begin{array}{l}{[46,747.57,} \\
58,926.27]\end{array}$ & $\begin{array}{l}{[45,908.44,} \\
58,926.27]\end{array}$ & $\begin{array}{l}{[45,728.61} \\
58,907.33]\end{array}$ & $\begin{array}{l}{[45,400.36,} \\
57,794.33]\end{array}$ \\
\hline & $\mathrm{h}=2$ & $\begin{array}{l}{[46,082.49,} \\
49,339.46]\end{array}$ & $\begin{array}{l}{[46,086.85,} \\
49,148.65]\end{array}$ & $\begin{array}{l}{[46,037.42,} \\
49,142.83]\end{array}$ & $\begin{array}{l}{[45,431.45,} \\
49,068.19]\end{array}$ & $\begin{array}{l}{[45,192.69,} \\
48,222.94]\end{array}$ \\
\hline & $\mathrm{h}=3$ & $\begin{array}{l}{[29,090.81,} \\
32,107.98]\end{array}$ & $\begin{array}{l}{[29,015.05} \\
32,015.54]\end{array}$ & $\begin{array}{l}{[29,015.05,} \\
32,015.54]\end{array}$ & $\begin{array}{l}{[29,015.05} \\
32,015.54]\end{array}$ & $\begin{array}{l}{[29,015.05,} \\
31,993.50]\end{array}$ \\
\hline \multirow{3}{*}{$t=2$} & $\mathrm{~h}=1$ & $\begin{array}{l}{[43,125.79,} \\
56,352.63]\end{array}$ & $\begin{array}{l}{[42,926.20,} \\
56,463.97]\end{array}$ & $\begin{array}{l}{[41,948.42,} \\
56,463.97]\end{array}$ & $\begin{array}{l}{[41,931.07,} \\
56,437.83]\end{array}$ & $\begin{array}{l}{[41,717.47,} \\
55,641.02]\end{array}$ \\
\hline & $h=2$ & $\begin{array}{l}{[38,890.91,} \\
46,190.99]\end{array}$ & $\begin{array}{l}{[38,994.84,} \\
46,433.57]\end{array}$ & $\begin{array}{l}{[38,064.14,} \\
46,424.53]\end{array}$ & $\begin{array}{l}{[37,789.90,} \\
46,354.70]\end{array}$ & $\begin{array}{l}{[37,038.71,} \\
46,126.27]\end{array}$ \\
\hline & $\mathrm{h}=3$ & $\begin{array}{l}{[27,892.07,} \\
30,590.55]\end{array}$ & $\begin{array}{l}{[27,695.09} \\
30,477.29]\end{array}$ & $\begin{array}{l}{[27,695.09,} \\
30,477.29]\end{array}$ & $\begin{array}{l}{[27,695.09,} \\
30,446.99]\end{array}$ & $\begin{array}{l}{[27,695.09,} \\
30,049.19]\end{array}$ \\
\hline \multirow{3}{*}{$t=3$} & $\mathrm{~h}=1$ & $\begin{array}{l}{[53,122.47,} \\
76,779.17]\end{array}$ & $\begin{array}{l}{[53,137.32,} \\
75,701.38]\end{array}$ & $\begin{array}{l}{[53,467.22,} \\
72,236.61]\end{array}$ & $\begin{array}{l}{[53,636.18,} \\
72,058.48]\end{array}$ & $\begin{array}{l}{[53,714.90,} \\
70,143.08]\end{array}$ \\
\hline & $h=2$ & $\begin{array}{l}{[64,159.80} \\
77,143.92]\end{array}$ & $\begin{array}{l}{[64,601.49,} \\
76,199.71]\end{array}$ & $\begin{array}{l}{[63,690.30,} \\
72,770.01]\end{array}$ & $\begin{array}{l}{[63,823.77,} \\
72,600.84]\end{array}$ & $\begin{array}{l}{[63,847.15,} \\
72,525.75]\end{array}$ \\
\hline & $h=3$ & $\begin{array}{l}{[68,971.33,} \\
71,230.94]\end{array}$ & $\begin{array}{l}{[65,884.16,} \\
70,614.86]\end{array}$ & $\begin{array}{l}{[62,650.05,} \\
67,134.40]\end{array}$ & $\begin{array}{l}{[61,506.59} \\
66,346.23]\end{array}$ & $\begin{array}{l}{[61,444.22,} \\
66,287.66]\end{array}$ \\
\hline
\end{tabular}

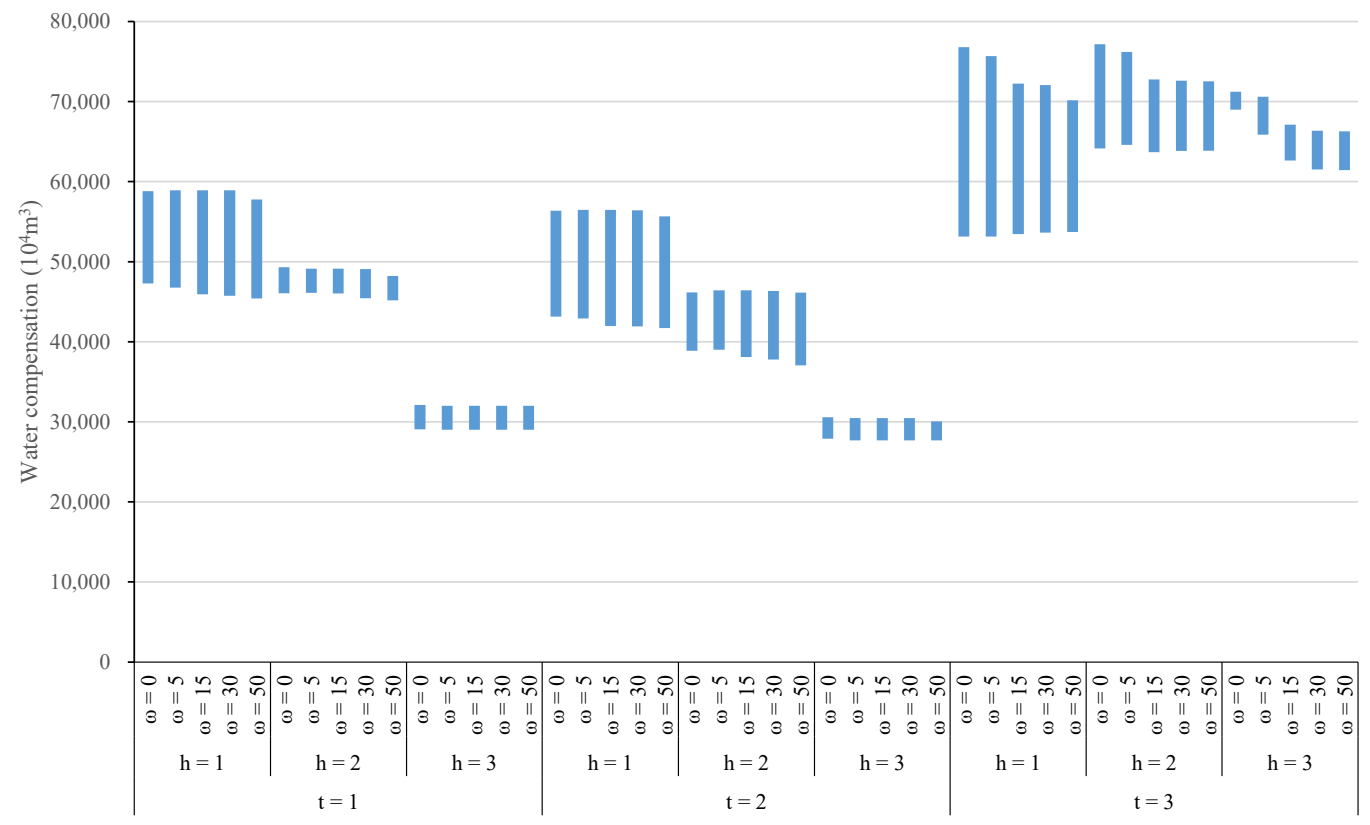

Figure 4. Water compensation for the Fenhe River Basin.

Figures 5-7 show the differences between the upstream, midstream, and downstream areas of the river in the three periods, respectively. The upstream area contains a small ecological water supply purifying excessive pollutant emission, whereas the midstream and downstream areas have large supplies. For example, in period 1 and scenario 3, the amounts of ecological water supplies are 0, [24,925.12, 27,376.22], and [4089.93, 4639.32] $\times 10^{4} \mathrm{~m}^{3}$ for an $\omega$ value of 30 . Therefore, despite relatively sufficient water resources and environmental carrying capacities, concentrated industries and a dense population associated with regional social economic development negatively impacts the water environment in the midstream and downstream areas. Consequently, socio-economic planning and water resource allocation should be subject to environmental water quality and water resources constraints. 


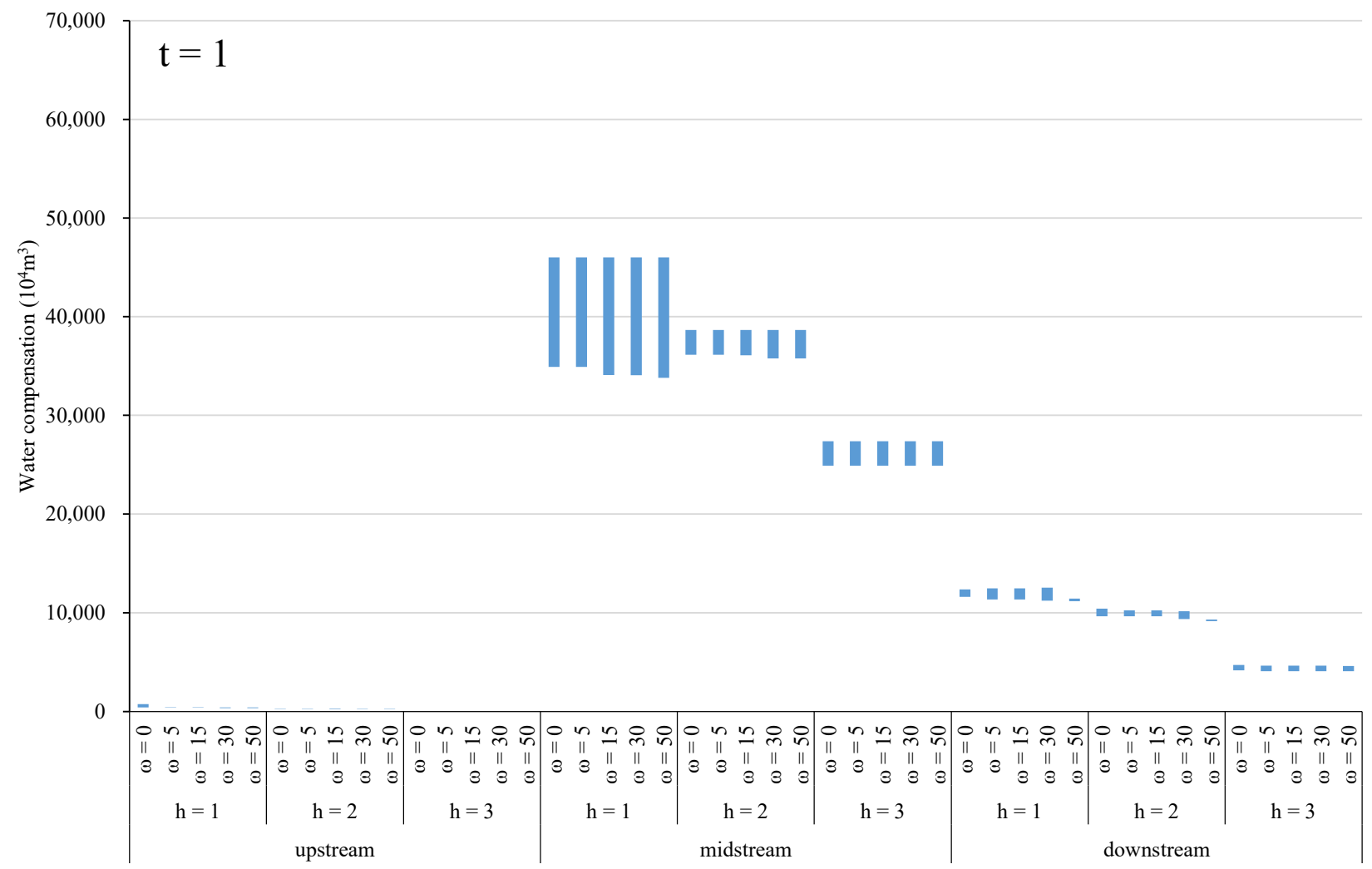

Figure 5. Water compensation by region in the Fenhe River Basin in period 1.

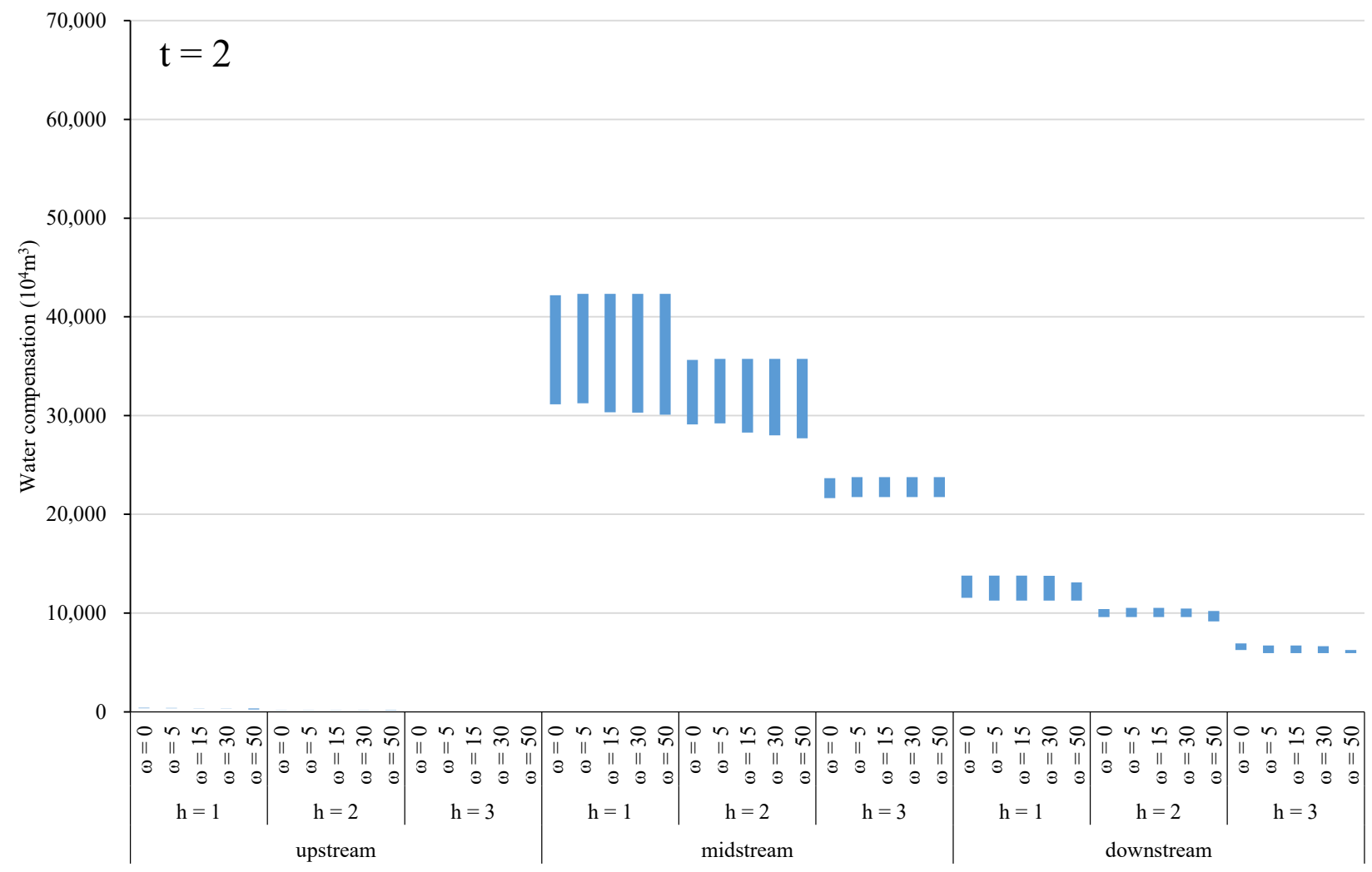

Figure 6. Water compensation by region in the Fenhe River Basin in period 2. 


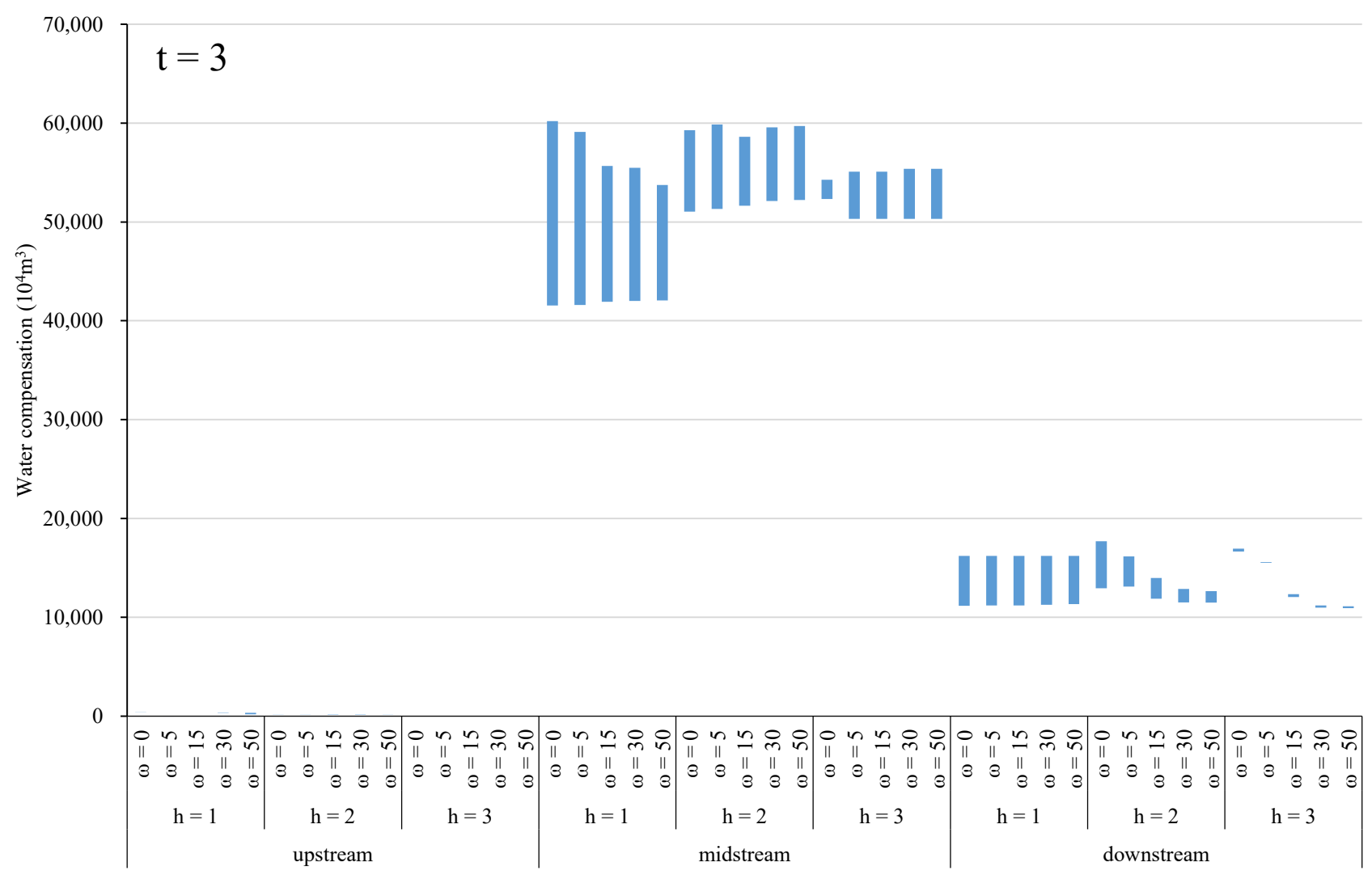

Figure 7. Water compensation by region in the Fenhe River Basin in period 3.

Figures 8-10 show water resource deficits for different sectors and regions caused by water shortages in different scenarios. Deficits primarily appear in the agriculture sector. In period 1, scenario 1, the industrial, domestic, agricultural, and environmental water deficits in the upstream area for an $\omega$ value of 30 were [233.02, 859.33], [11.36, 63.98], [3234.05, $8424.18]$, and $[30.31,380.93] \times 10^{4} \mathrm{~m}^{3}$, respectively. Due to relatively low benefit, the water resources are prioritized for high benefit and environmental sectors to ensure the minimum water demands formulated by decision-makers. As $\omega$ values increase, water deficits generate different changes by sector. When all other conditions in the abovementioned analysis remain unchanged, $\omega$ values of 15 and 50 yield industrial, domestic, agricultural and environmental water deficits of $[100.75,498.28]$ and $[233.02,499.18] \times 10^{4} \mathrm{~m}^{3},[0,96.84]$ and $[11.368,63.98] \times 10^{4} \mathrm{~m}^{3}$, [3846.21, 8577.93] and [3170.95, 8366.48] $\times 10^{4} \mathrm{~m}^{3}$, and [30.31, 395.47] [380.93, 395.86] $\times 10^{4} \mathrm{~m}^{3}$, respectively. Industrial, domestic, agricultural, and environmental water deficits fluctuate, remain unchanged, significantly decrease, and significantly increase, respectively. Risk analysis reveals that the positive deviation from the expected industrial, domestic, and environmental benefits remains stable. Additionally, the agricultural values decrease significantly, which translates to decreases regional risk. Although the industrial water deficit increases, the total water resources used for industry could be replenished by recycled water. Additionally, decreasing the benefit does not imply increasing risk, due to sufficient pre-allocation of water resources or relatively conservative expected benefits. Consequently, the ITSDP model can adjust the water resource allocations for risk control. 


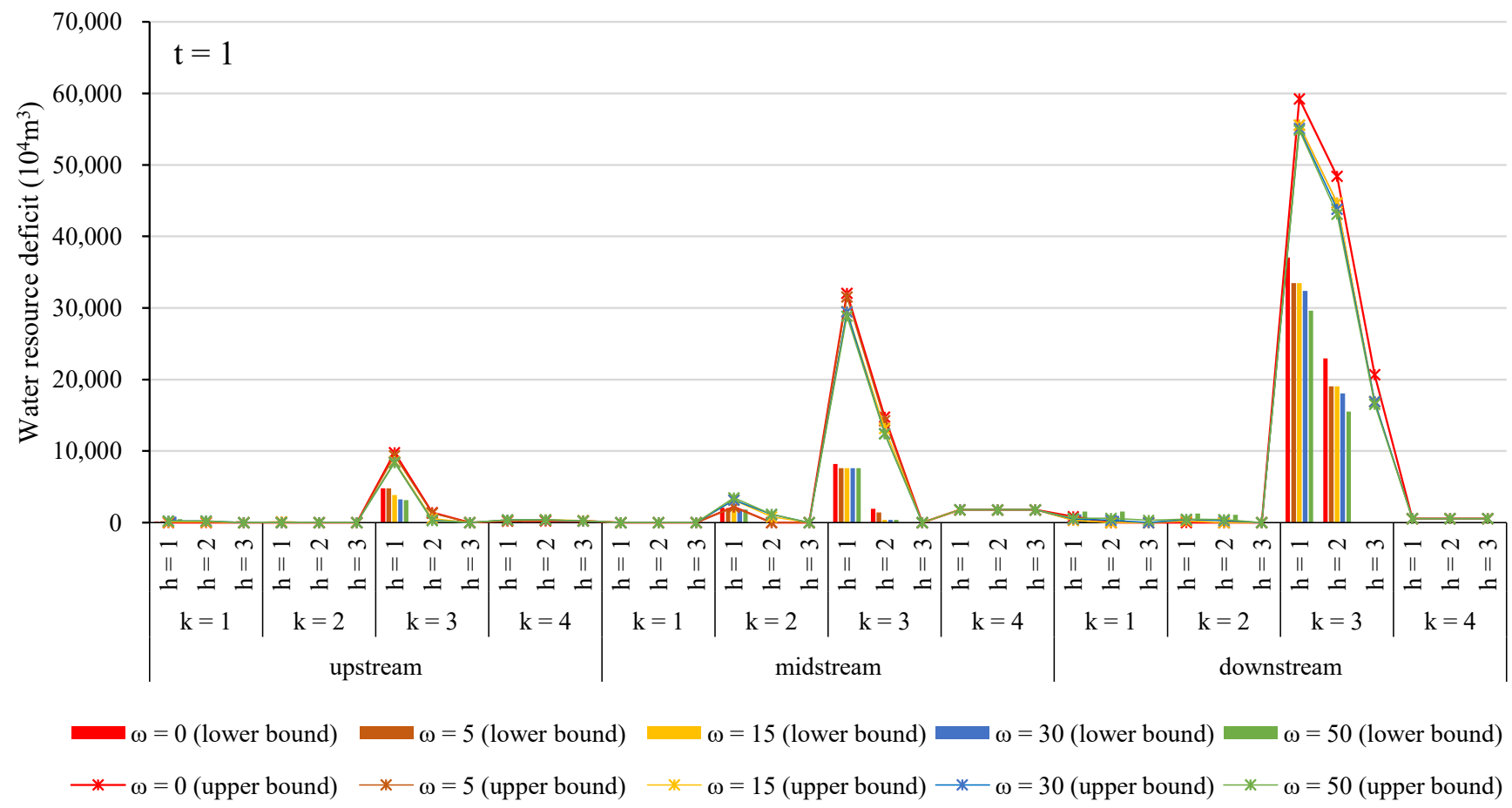

Figure 8. Water resource deficit by region in the Fenhe River Basin in period 1.

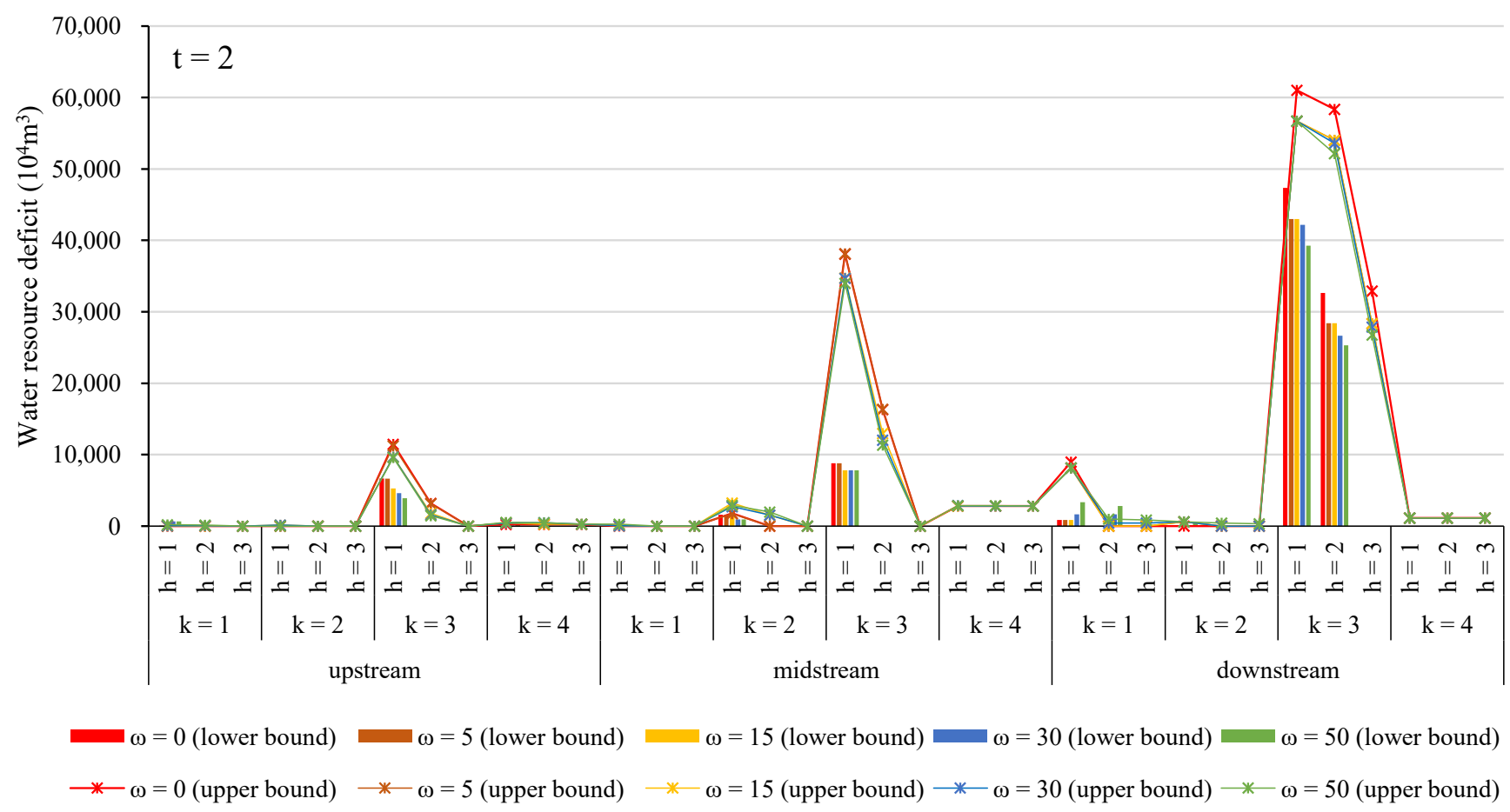

Figure 9. Water resource deficit by region in the Fenhe River Basin in period 2. 


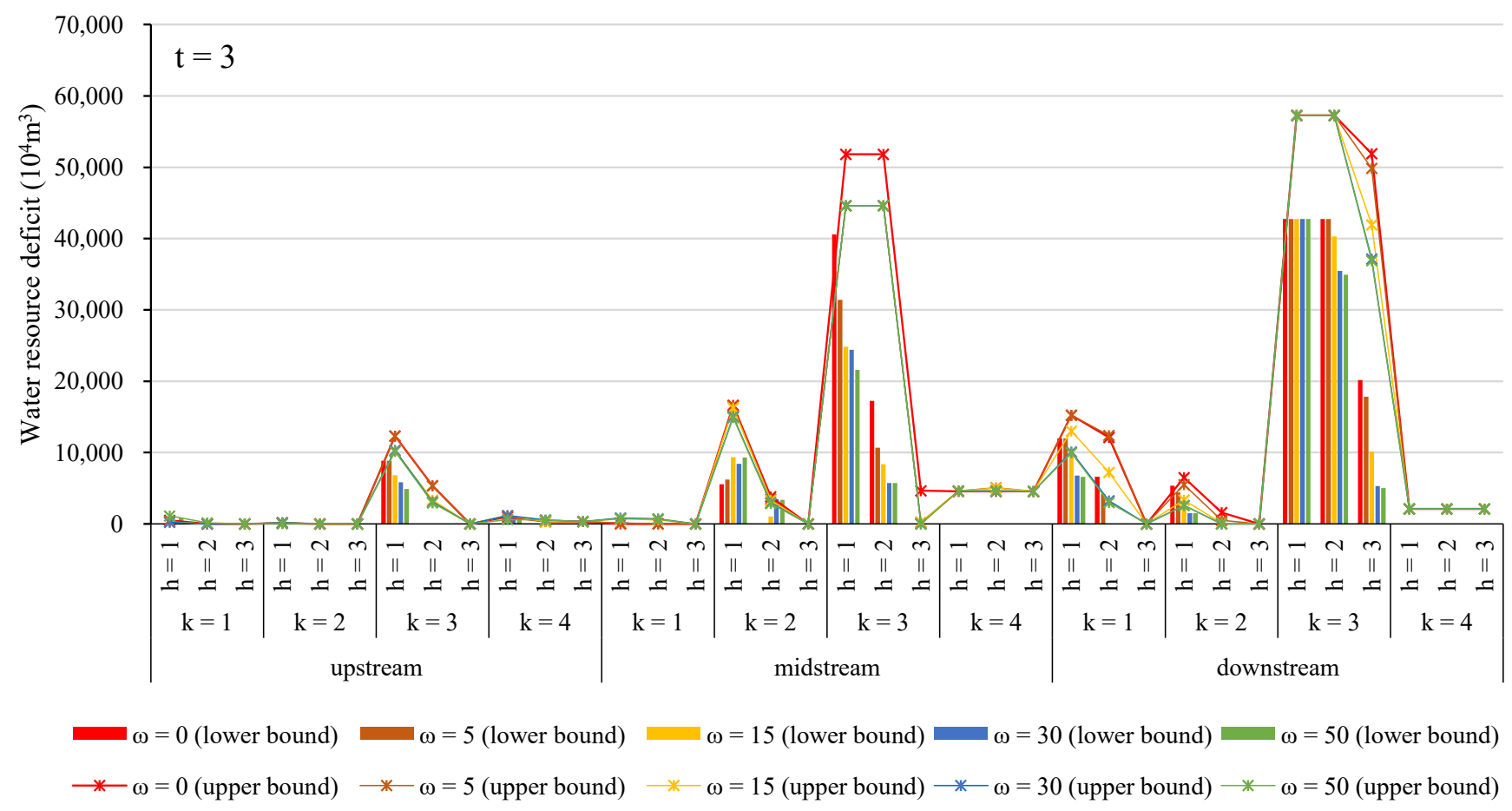

Figure 10. Water resource deficits by region in the Fenhe River Basin in period 3.

Figures 11-13 show reused water resources by sector and region. Reused water resources are primarily allocated to industrial and domestic use, and the amounts increase with time. Reused water resources for the Fenhe River Basin in scenario 1 for $\omega$ values of 0,15 , and 30 were $[12,084.09,12,206.67]$, [11,920.16, 12,233.1], and [11,851.42, 12,169.68] $\times 10^{4} \mathrm{~m}^{3}$ in period $1 ;[18,120.25,18,162.71],[17,600.76,18,274.65]$, and $[17,592.03,18,274.65]$ $\times 10^{4} \mathrm{~m}^{3}$ in period 2; and [15,809.45, 19,577.92], [15,881.99, 18,438.54], and [15,891.47, $18,378.19] \times 10^{4} \mathrm{~m}^{3}$ in period 3 , respectively. As $\omega$ values increase, the amount of reused water decreases, perhaps because water resources are allocated to the agricultural and environmental sectors to decrease regional risks and to balance socio-economic development, because these sectors have few renewable water production capacities. Moreover, the allocation of water resources by sectors varies by region, indicating optimal regulation of water resources among sectors using the ITSDP model. Reused industrial water resources in period 1, scenario 1 for $\omega$ values of 0,15 , and 30 were [465.83, 620.13], [435.66, 645.74], and $[229.59,588.67] \times 10^{4} \mathrm{~m}^{3} ; 181.51,76.45$, and $[69.96,258.9] \times 10^{4} \mathrm{~m}^{3}$; and $[4.62,58.17]$, $[101.92,295.54]$, and $[101.92,281.01] \times 10^{4} \mathrm{~m}^{3}$, respectively (Figure 11). Similar sectoral changes at different risk control levels do not occur for domestic and agricultural water resources. Furthermore, as available water resources change, water resource allocation strategies generate various regulations. As available water resources increase in period 1 for $\omega$ of 50, the reused industrial and domestic water amounts of [229.59, 223.13], [229.59, 283.14], and [128.84, 283.14] $\times 10^{4} \mathrm{~m}^{3}$ and [258.9, 69.96], [258.9, 386.37], and [386.37, 386.37] $\times 10^{4} \mathrm{~m}^{3}$ increase. Conversely, the amounts of reused environmental water ([281.01, 467.47], [281.01, 71.61], [155.47, 71.61] $\times 10^{4} \mathrm{~m}^{3}$ ) decrease. Thus, for severe water resource deficiency, fresh water should be first allocated to production sectors to ensure regional development and to provide enough renewable water resources to the environmental sector. 


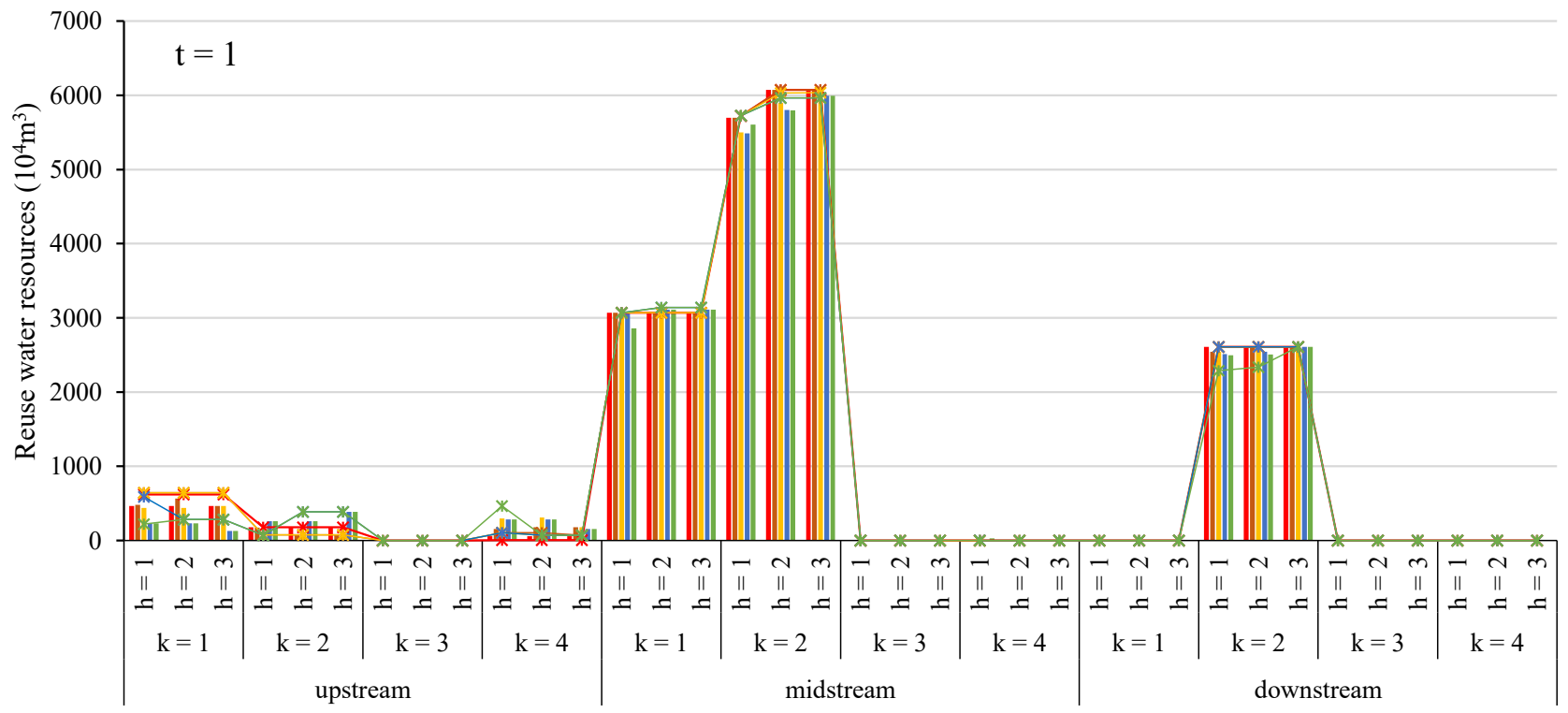

$$
\begin{aligned}
& \omega=0 \text { (lower bound) } \omega=5 \text { (lower bound) } \omega=15 \text { (lower bound) } \omega \omega=30 \text { (lower bound) } \omega=50 \text { (lower bound) } \\
& \text { * } \omega=0 \text { (upper bound) } \rightarrow \omega=5 \text { (upper bound) } \rightarrow \omega=15 \text { (upper bound) } \rightarrow \omega=30 \text { (upper bound) } \rightarrow \omega=50 \text { (upper bound) }
\end{aligned}
$$

Figure 11. Reused water resources by region in the Fenhe River Basin in period 1.

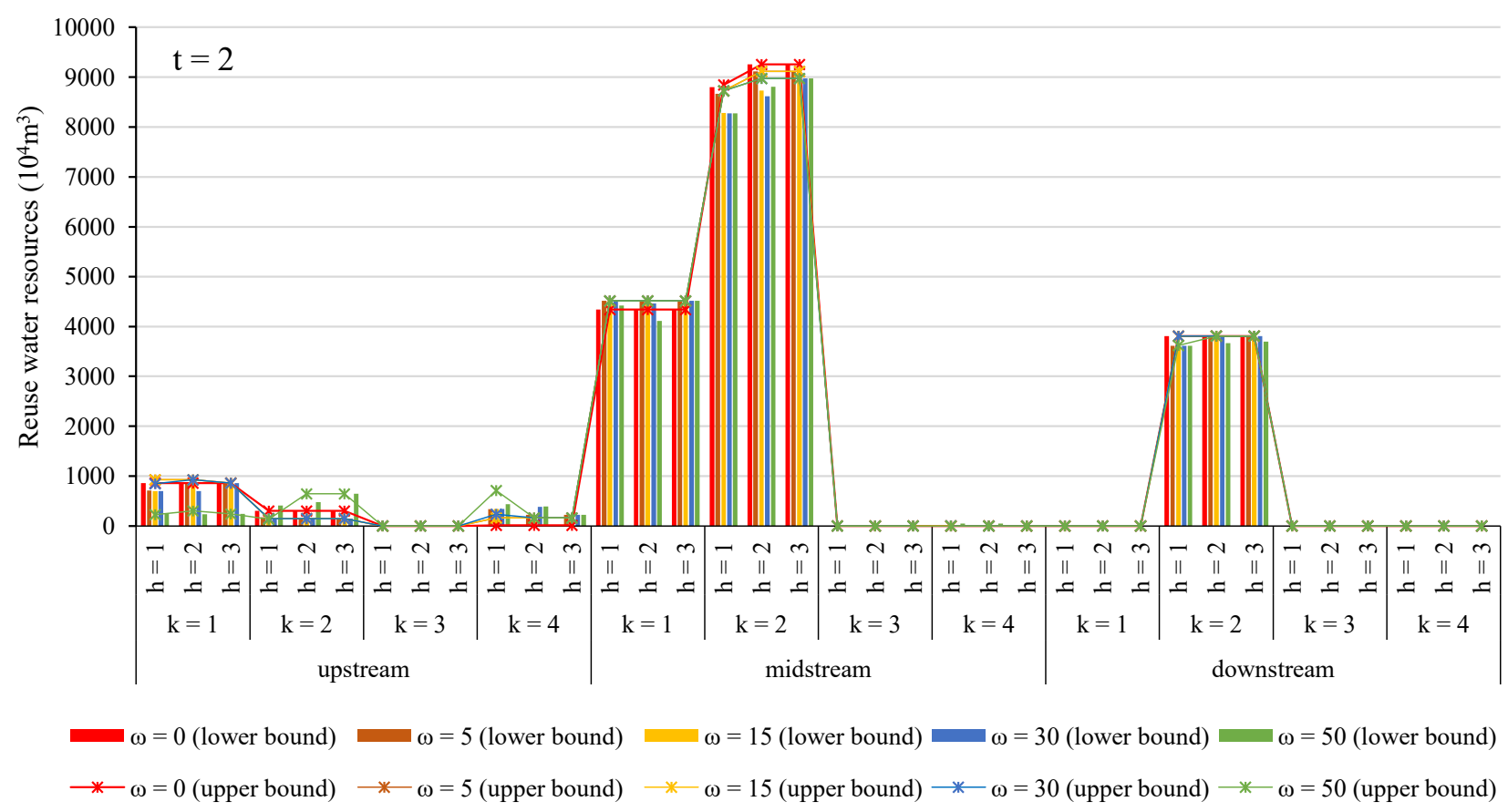

Figure 12. Reused water resources by region in the Fenhe River Basin in period 2. 


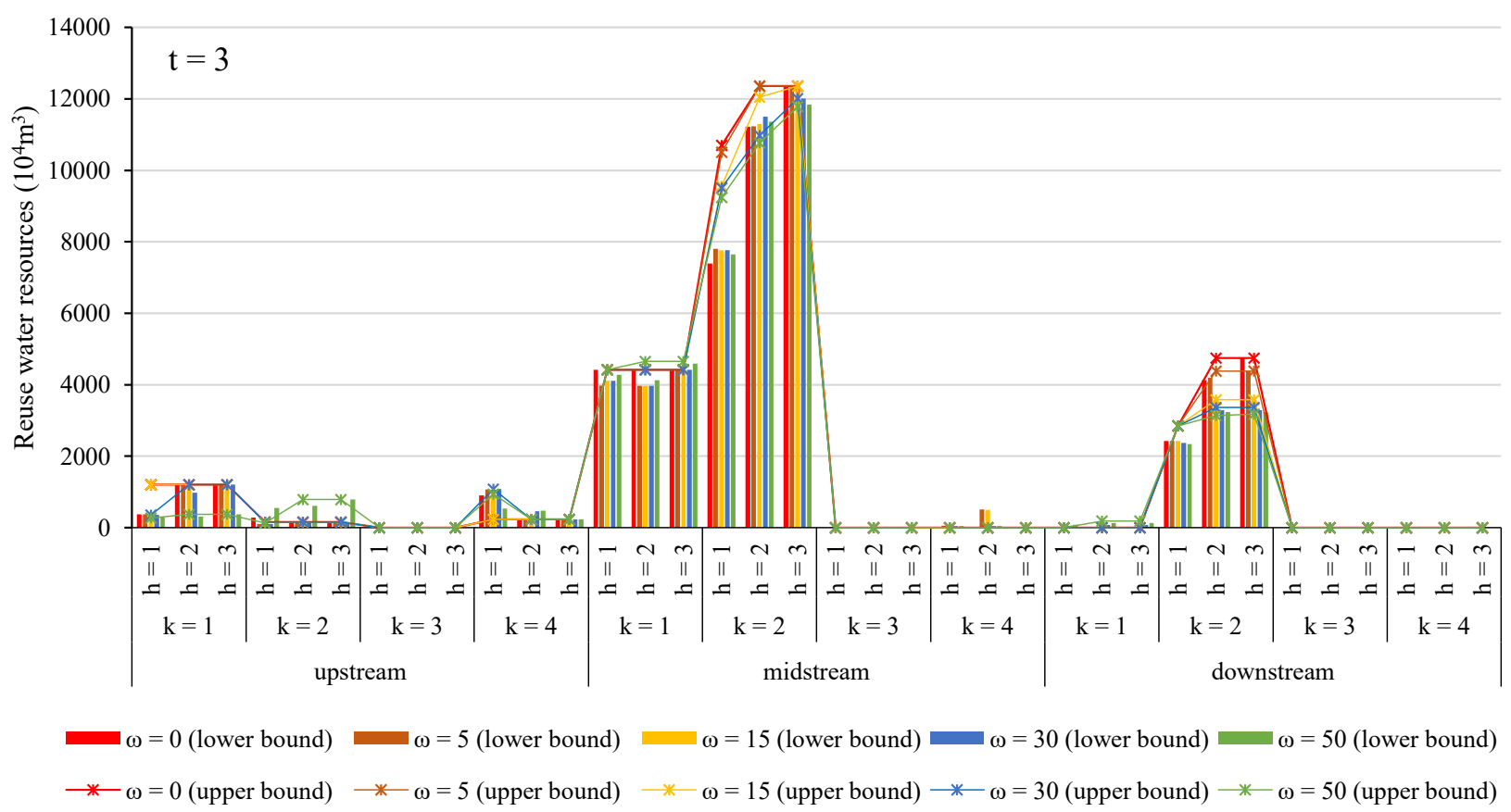

Figure 13. Reused water resources for by region in the Fenhe River Basin in period 3.

\subsection{Policy Interventions and Analysis}

This study demonstrates that water resources are insufficient to support regional socio-economic development and to ensure environmental quality in the Fenhe River Basin; furthermore, reused water is a key factor for addressing the water shortages. To reflect optimal regulation under severe water shortage conditions, we consider an $\omega$ value of 15 and low water resource level $(\mathrm{h}=1)$ as the baseline scenario (S1). In another policy scenario, S2, the water reuse rate gradually increases to at least 0.4 , in period 3 .

Finally, the risks (Table 5) are CNY $[0.09,0.18]$ and $[0.08,0.16] \times 10^{6}$ million in period 1 , CNY $[0.08,0.39]$ and $[0.05,0.37] \times 10^{6}$ million in period 2 , and CNY $[10.22,14.67]$ and $[10.36$, 14.77] $\times 10^{6}$ million in period 3 . The results indicate that an improved water reuse rate (S2) could increase benefits and control regional and sectoral risks. Additionally, improved water reuse rates could provide support for decision-makers for the optimal regulation of water resources in the Fenhe River.

Table 5. Benefits of water resource utilization and risks in the Fenhe River Basin $\left(10^{6}\right.$ million).

\begin{tabular}{cccc}
\hline & & \multicolumn{2}{c}{ Scenarios } \\
\cline { 3 - 4 } & & Seriods & S2 \\
\hline \multirow{3}{*}{ Benefits } & $\mathrm{t}=1$ & {$[5.89,6.68]$} & {$[5.91,6.69]$} \\
& $\mathrm{t}=2$ & {$[8.23,10.46]$} & {$[8.25,10.51]$} \\
& $\mathrm{t}=3$ & {$[10.22,14.67]$} & {$[10.36,14.77]$} \\
\hline \multirow{2}{*}{ Risks } & $\mathrm{t}=1$ & {$[0.09,0.18]$} & {$[0.08,0.16]$} \\
& $\mathrm{t}=2$ & {$[0.08,0.39]$} & {$[0.05,0.37]$} \\
& $\mathrm{t}=3$ & {$[0.54,2.07]$} & {$[0.51,1.94]$} \\
\hline
\end{tabular}

Figure 14 shows water resource deficits in different scenarios. The significant decrease of the agricultural water deficit means the alleviation of water shortages in this sector. For example, in period 1, the agricultural water deficit in the midstream area decrease from $[7840.42,29,532.58] \times 10^{4} \mathrm{~m}^{3}$ to $[7851.50,25,973.52] \times 10^{4} \mathrm{~m}^{3}$. Additionally, the domestic value decreases from $[1774.86,3130.60] \times 10^{4} \mathrm{~m}^{3}$ to $[1555.35,2863.89] \times 10^{4} \mathrm{~m}^{3}$; therefore, more reclaimed water can be allocated for these sectors. However, the few industrial 
changes denote less water compensation for the environment; therefore, improving the water reuse capacity can alleviate water resource shortages and reduce pollution emissions.
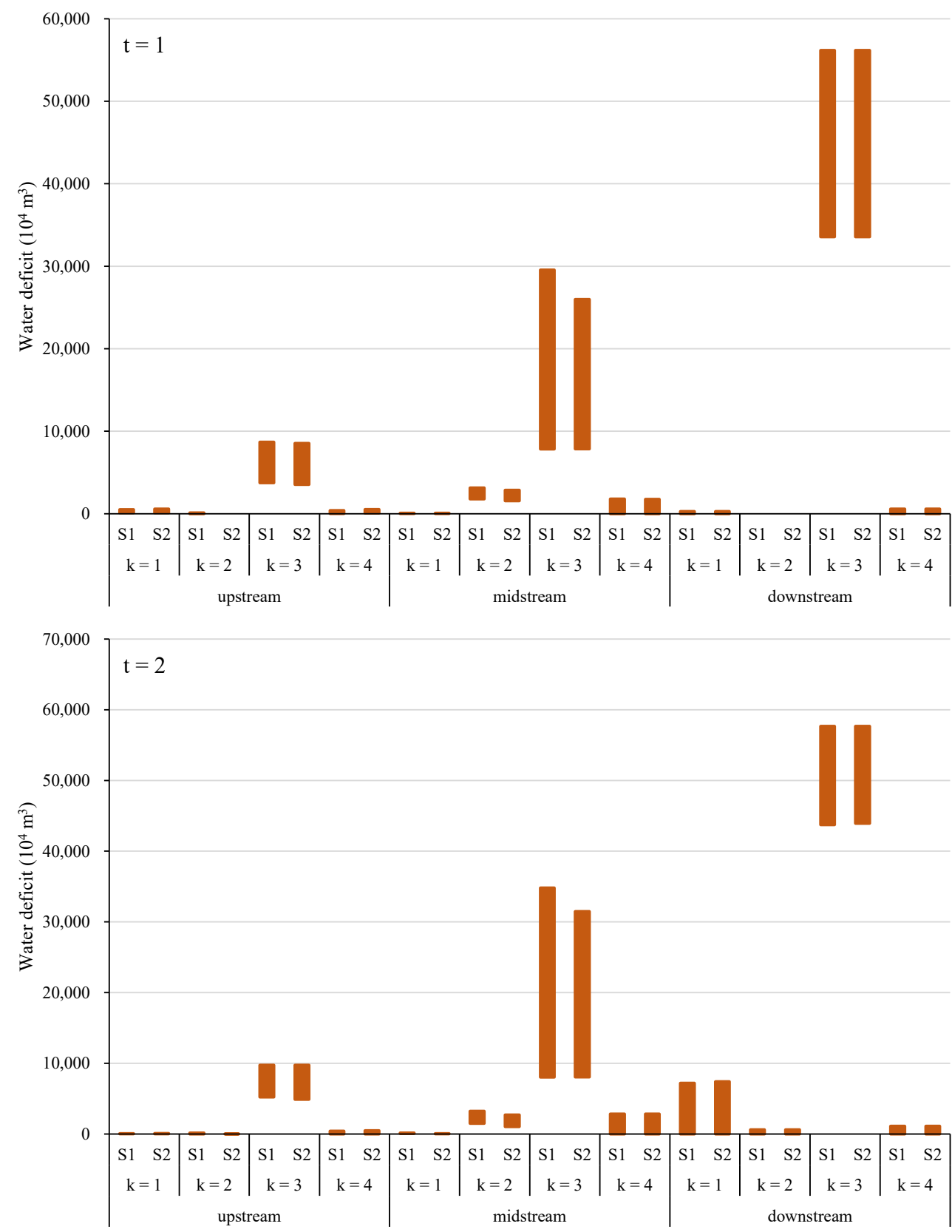

Figure 14. Cont. 


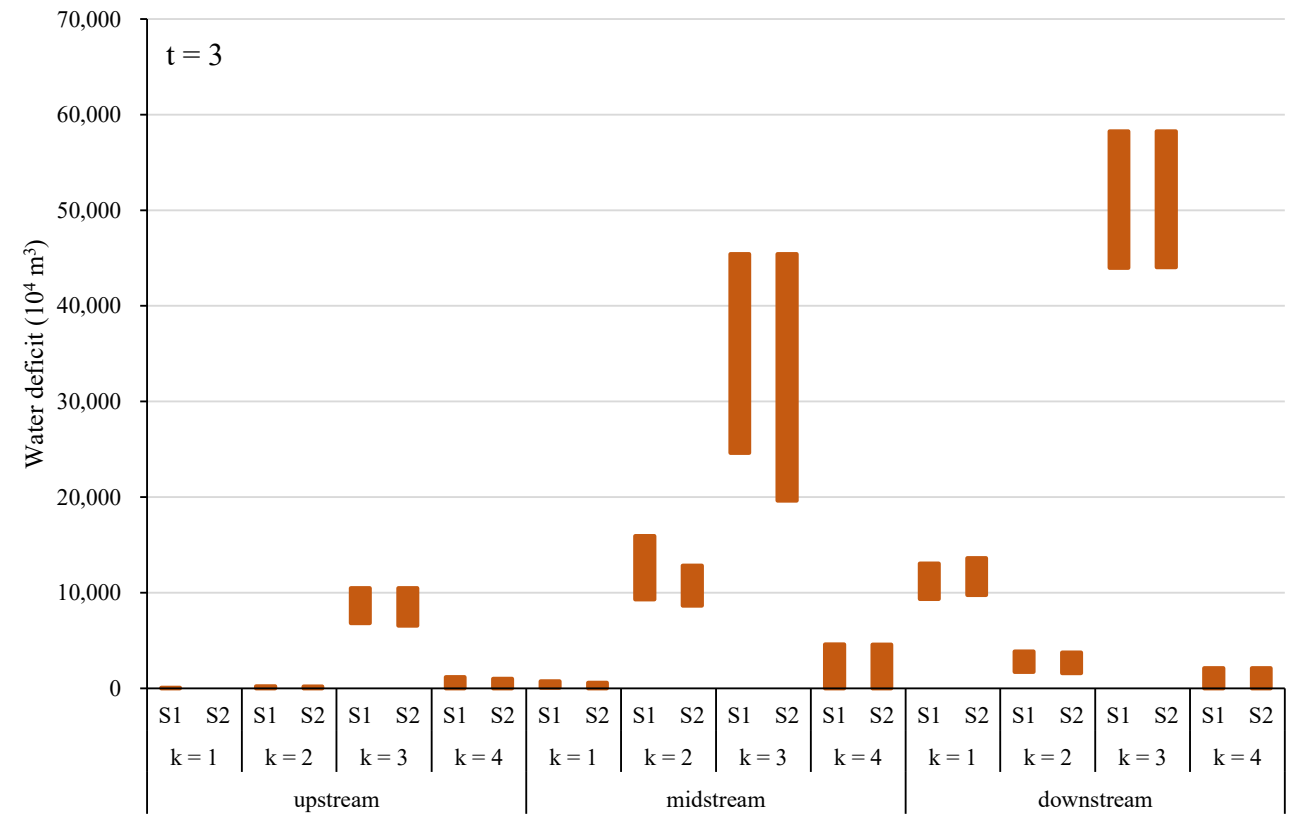

Figure 14. Water resource deficits in the Fenhe River Basin by scenario.

Figure 15 shows reused water resources in different scenarios. The water deficits analysis revealed a synergetic change in water resource allocation for the environmental sector. In period 1 , the environmental water deficits were [30.31,395.47] and [67.29, 537.90] $\times 10^{4} \mathrm{~m}^{3}$, and the reused water resources were [101.92, 295.54] and [137.90, 438.69] $\times 10^{4}$ $\mathrm{m}^{3}$; the same values apply to the midstream and downstream areas and other periods. These results could be caused by not considering the benefits of the environment sector and to the strong water demand in this study. Additionally, S2 has a higher reused water rate; thus, the environmental demand in this scenario was supplied by reused water resources.

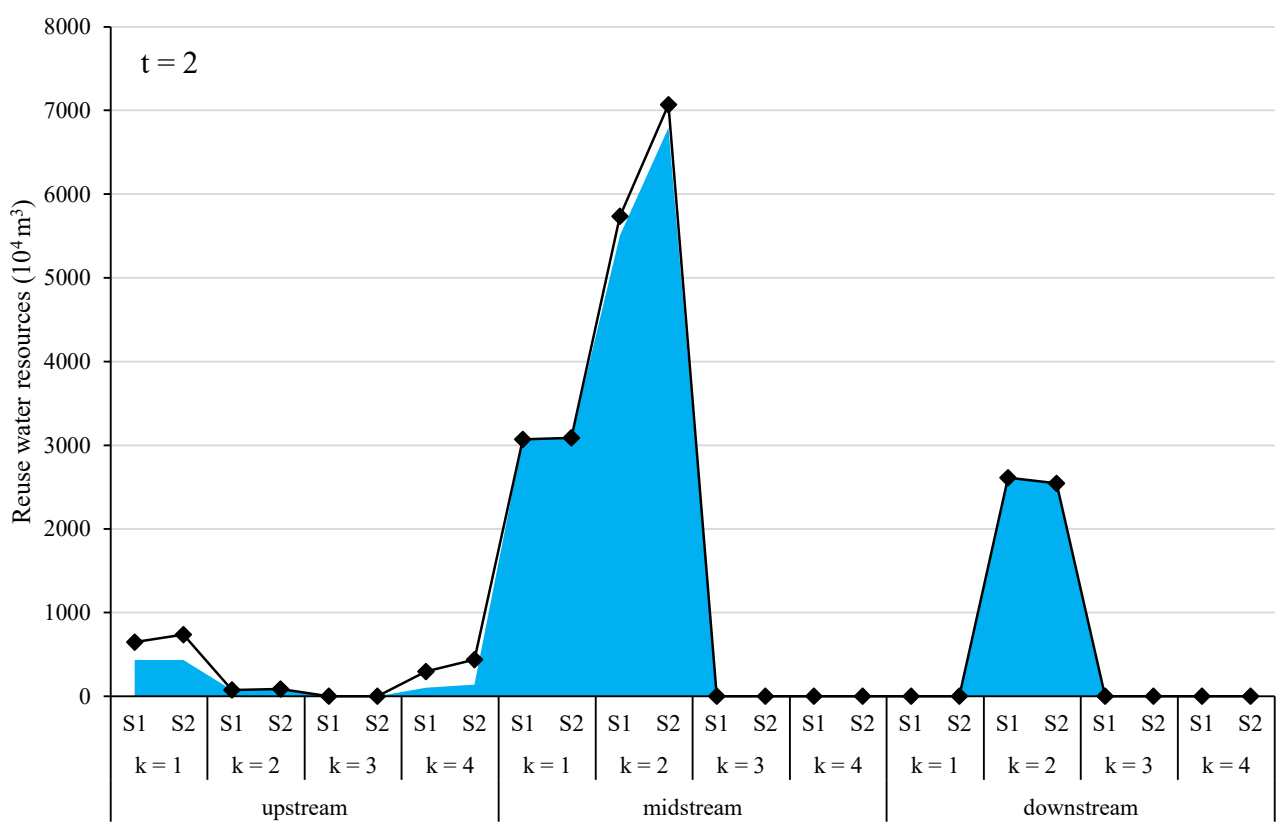

Figure 15. Cont. 

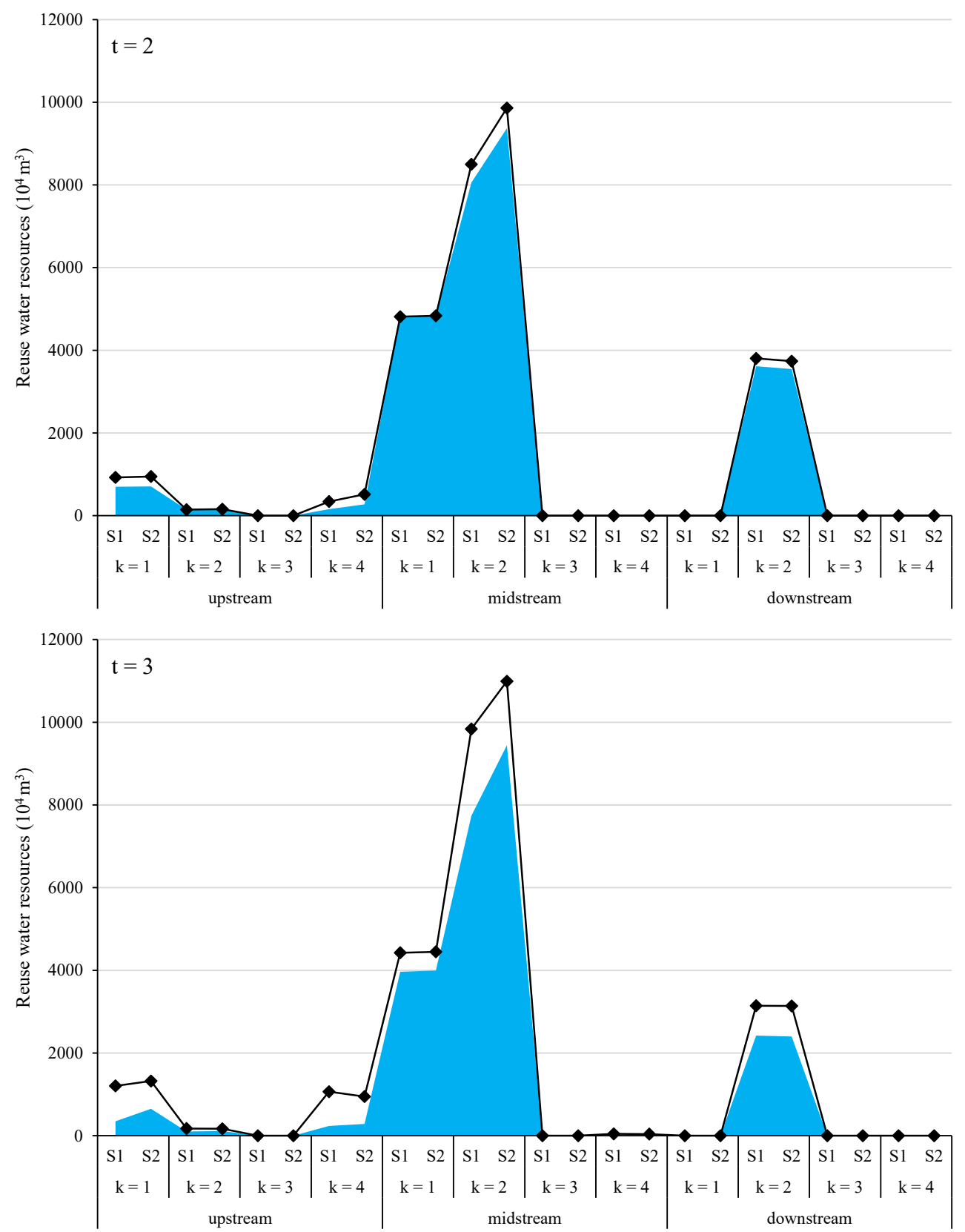

Figure 15. Reuse water resources in the Fenhe River Basin by scenario.

Figure 16 shows that improving the water reuse capacity reduces pollution emissions. The water compensation in the midstream area in S2, period 1 is significantly lower $\left([31,367.80,42,790.44] \times 10^{4} \mathrm{~m}^{3}\right)$ than that in $\mathrm{S} 1\left([34,046.38,46,012.89] \times 10^{4} \mathrm{~m}^{3}\right)$; the same is true of the upstream and downstream areas. The results show that appropriate policy interventions, such as improving reclaimed water use, would further optimize water resource allocation and effectively alleviate water shortages and water pollution in the Fenhe River Basin. 


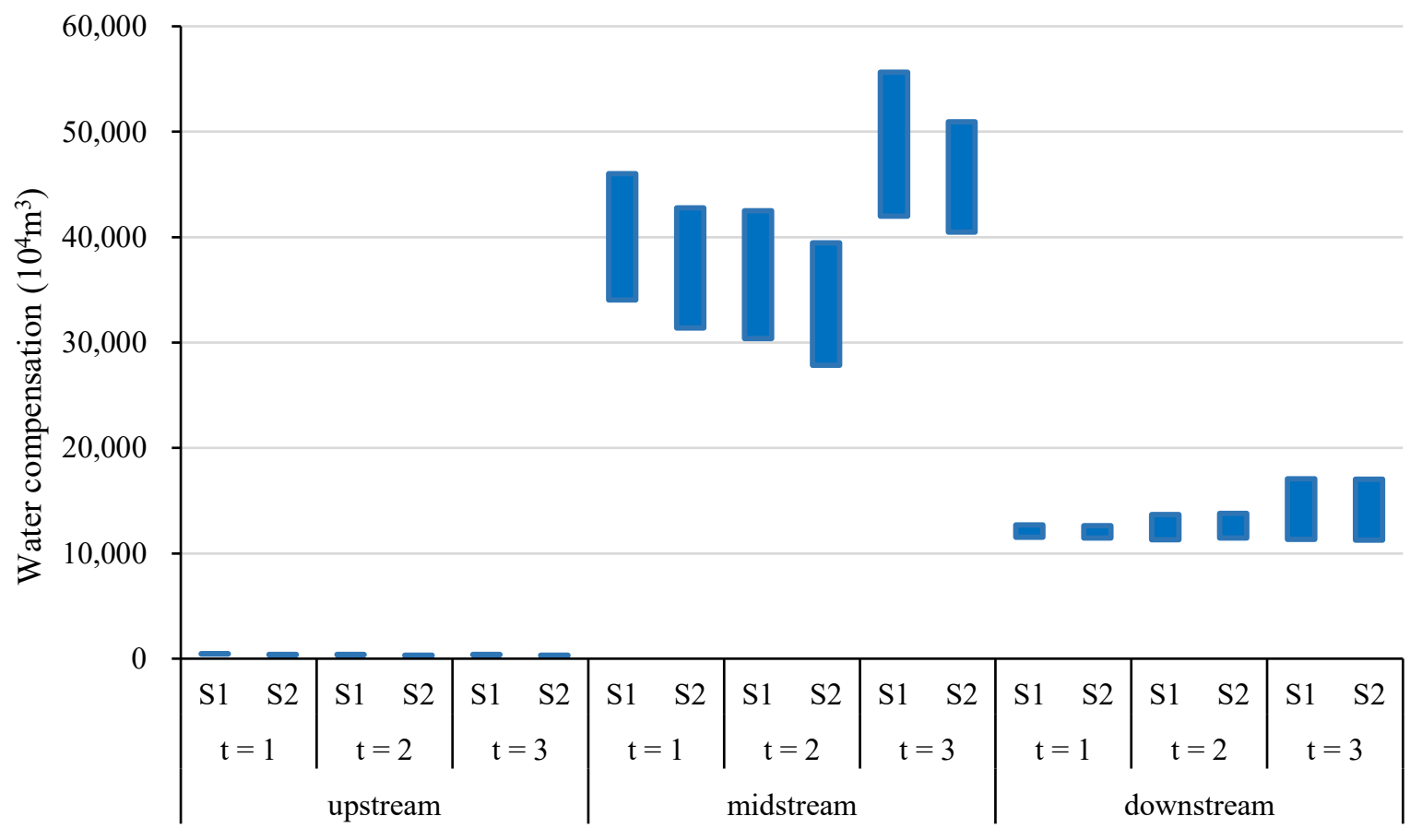

Figure 16. Water compensation in the Fenhe River Basin under different scenarios.

\section{Conclusions}

The irrational use of water resources has exacerbated serious problems, such as environmental water shortages and cross-sector competition for water resources in many river basins, and water resource allocation aimed at sustainable watershed development suffers from the dual challenges of water pollution and scarcity. In this study, an improved ITSDP model was built to optimize water resource allocation strategies under the dual challenges and uncertainties in the Fenhe River Basin, which is a highly urbanized, densely populated, but typical water-deprived area with a high degree of contamination. The proposed model simultaneously addresses the uncertainties presented as interval values and probability distributions by integrating the IPP and TSP methods. The introduction of the downside risk method effectively avoids possible sectoral risks caused by uneven water resource allocation, and different risk levels and with different policy interventions (S2) all reflect the preference of decision makers for regional socio-economic development, environmental protection, regional planning and policy-making. By solving the ITSDP model, optimal water resource allocations for the primary water use sectors were determined for the planning periods under different scenarios. Additionally, we obtained the water compensation strategies for purifying excessive pollutant emissions subject to strong water quality constraints. These results suggest that the ITSDP model is applicable to address the complexity of water resource management and reflect the attitude of decision makers, it can be used for providing support for optimizing desired water resource allocation strategies and resolving the sectoral water conflicts and environmental problems in the Fenhe River Basin.

The aim of this study was to use the ITSDP model to develop an effective approach to determine and optimize water resource allocations, and the coordination of water quality protection and socio-economic development could support the further establishment of water-based industrial structures and layouts. Although the results suggest that this approach is applicable and effective to address such dual constraints and water conflicts in the Fenhe River Basin and could also be applied in other contexts or water-stressed areas, there is still space for improvement of the model. This model does not fully consider the role of human agency in conflicts. In addition, details such as interaction between water utilizations and climate change were not addressed in this model, and the finally pollutant emissions based the optimized water allocation strategies should be deeply analyzed for 
providing a basis for a regional emission permit system. Further studies are needed to address these limitations.

Author Contributions: Conceptualization, W.L. and C.M.; methodology, C.M.; software, C.M.; validation, C.M., R.C. and S.Z.; formal analysis, C.M.; investigation, C.M.; resources, R.C.; data curation, R.C.; writing—original draft preparation, C.M.; writing—review and editing, C.M.; visualization, S.Z.; supervision, W.L.; project administration, W.L.; All authors have read and agreed to the published version of the manuscript.

Funding: This research was funded by the National Natural Science Foundation of China (Grant No. 72050001).

Conflicts of Interest: The authors declare no conflict of interest.

\section{References}

1. Edda, K.; Thomas, K.; Olaf, K.; Elisabeth, K.; Jörg, S.; Gunda, R.; Georg, T.; Dietrich, B.; Peter, K. Integrated Water Resources Management under different hydrological, climatic and socio-economic conditions. Environ. Earth Sci. 2012, 65, 1363-1366.

2. Tang, L.; Yang, D.; Hu, H.; Gao, B. Detecting the effect of land-use change on streamflow, sediment and nutrient losses by distributed hydrological simulation. J. Hydrol. 2011, 409, 172-182. [CrossRef]

3. Zhang, H.; Lu, P.; Zhang, D.; Kou, S.; Mao, Y. Watershed-scale assessment of surface water-related risks from shale gas development in mountainous areas, China. J. Environ. Manag. 2020, 279, 111589. [CrossRef]

4. Liu, L.; Ma, J.; Hao, X.; Li, Q. Limitations of Water Resources to Crop Water Requirement in the Irrigation Districts along the Lower Reach of the Yellow River in China. Sustainability 2019, 11, 4680. [CrossRef]

5. Wei, F.; Zhang, X.; Xu, J.; Bing, J.; Pan, G. Simulation of water resource allocation for sustainable urban development: An integrated optimization approach. J. Clean. Prod. 2020, 273, 122537. [CrossRef]

6. Su, D.; Zhang, Q.H.; Ngo, H.H.; Dzakpasu, M.; Guo, W.S.; Wang, X.C. Development of a water cycle management approach to Sponge City construction in Xi'an, China. Sci. Total Environ. 2019, 685, 490-496. [CrossRef] [PubMed]

7. Li, J.; See, K.F.; Chi, J. Water resources and water pollution emissions in China's industrial sector: A green-biased technological progress analysis. J. Clean. Prod. 2019, 229, 1412-1426. [CrossRef]

8. Choi, I.-C.; Shin, H.-J.; Nguyen, T.T.; Tenhunen, J. Water Policy Reforms in South Korea: A Historical Review and Ongoing Challenges for Sustainable Water Governance and Management. Water 2017, 9, 717. [CrossRef]

9. Tian, J.; Guo, S.; Liu, D.; Pan, Z.; Hong, X. A Fair Approach for Multi-Objective Water Resources Allocation. Water Resour. Manag. 2019, 33, 3633-3653. [CrossRef]

10. Qin, J.; Fu, X.; Peng, S.; Huang, S. An Integrated Decision Support Framework for Incorporating Fairness and Stability Concerns into River Water Allocation. Water Resour. Manag. 2020, 34, 211-230. [CrossRef]

11. Wilby, R.L. Uncertainty in water resource model parameters used for climate change impact assessment. Hydrol. Process. 2010, 19, 3201-3219. [CrossRef]

12. Hart, O.E.; Halden, R.U. On the need to integrate uncertainty into U.S. water resource planning. Sci. Total Environ. 2019, 691, 1262-1270. [CrossRef] [PubMed]

13. Yao, L.; Xu, Z.; Chen, X. Sustainable Water Allocation Strategies under Various Climate Scenarios: A Case Study in China. J. Hydrol. 2019, 574, 529-543. [CrossRef]

14. Karmakar, S.; Mujumdar, P.P. An inexact optimization approach for river water-quality management. J. Environ. Manag. 2006, 81, 233-248. [CrossRef] [PubMed]

15. Li, Y.P.; Huang, G.H.; Nie, S.L. An interval-parameters multi-stage stochastic programming model for water resources management under uncertainty. Adv. Water. Resour. 2006, 29, 776-789. [CrossRef]

16. Qin, X.; Huang, G.; Chen, B.; Zhang, B. An interval-parameter waste-load-allocation model for river water quality management under uncertainty. Environ. Manag. 2009, 43, 999. [CrossRef]

17. Xie, Y.L.; Li, Y.P.; Huang, G.H.; Li, Y.F.; Chen, L.R. An inexact chance-constrained programming model for water quality management in Binhai New Area of Tianjin, China. Sci. Total Environ. 2011, 409, 1757-1773. [CrossRef]

18. Huang, G.H.; Loucks, D.P. An inexact two stage stochastic programming model for water resources management under uncertainty. Civ. Eng. Environ. Syst. 2000, 17, 95-118. [CrossRef]

19. Maqsood, I.; Huang, G.H.; Huang, Y.F.; Chen, B. ITOM: An interval parameter two-stage optimization model for stochastic planning of water resources systems. Stoch. Environ. Res. Risk Assess. 2005, 19, 125-133. [CrossRef]

20. Xu, Y.; Huang, G.H.; Qin, X.S. Inexact two-stage stochastic robust optimization model for water resources management under uncertainty. Environ. Eng. Sci. 2009, 26, 1765-1776. [CrossRef]

21. Li, W.; Li, Y.P.; Li, C.H.; Huang, G.H. An inexact two-stage water management model for planning agricultural irrigation under uncertainty. Agric. Water Manag. 2010, 97, 1905-1914. [CrossRef]

22. Wang, S.; Huang, G.H. Interactive two-stage stochastic fuzzy programming for water resources management. J. Environ. Manag. 2011, 92, 1986-1995. [CrossRef] [PubMed] 
23. Xie, Y.L.; Huang, G.H.; Li, W.; Li, J.B.; Li, Y.F. An inexact two-stage stochastic programming model for water resources management in Nansihu Lake Basin, China. J. Environ. Manag. 2013, 127, 188-205. [CrossRef] [PubMed]

24. Li, J.; Qiao, Y.; Lei, X.; Kang, A.; Wang, M.; Liao, W.; Wang, H.; Ma, Y. A two-stage water allocation strategy for developing regional economic-environment sustainability. J. Environ. Manag. 2019, 244, 189-198. [CrossRef]

25. Sarband, E.M.; Araghinejad, S.; Attari, J. Developing an Interactive Spatial Multi-Attribute Decision Support System for Assessing Water Resources Allocation Scenarios. Water Resour. Manag. 2020, 34, 447-462. [CrossRef]

26. Xie, Y.L.; Huang, G.H. Development of an inexact two-stage stochastic model with downside risk control for water quality management and decision analysis under uncertainty. Stoch. Environ. Res. Risk Assess. 2014, 28, 1555-1575. [CrossRef]

27. Harlow, W.V. Asset Allocation in a Downside-Risk Framework. Financ. Anal. J. 1991, 47, 28-40. [CrossRef]

28. Park, J.; Park, S.; Yun, C.; Kim, Y. Integrated model for financial risk management in refinery planning. Ind. Eng. Chem. Res. 2009, 49, 129. [CrossRef]

29. Finger, R. Expanding risk consideration in integrated models-the role of downside risk aversion in irrigation decisions. Environ. Model. Softw. 2013, 43, 169-172. [CrossRef]

30. Lee, S.Y.; Lee, I.B.; Han, J. Design under uncertainty of carbon capture, utilization and storage infrastructure considering profit, environmental impact, and risk preference. Appl. Energy 2019, 238, 34-44. [CrossRef] 